\title{
Three C. elegans Rac proteins and several alternative Rac regulators control axon guidance, cell migration and apoptotic cell phagocytosis
}

\author{
Erik A. Lundquist ${ }^{1, *}, \neq$, Peter W. Reddien ${ }^{2, *}$, Erika Hartwieg ${ }^{2}$, H. Robert Horvitz ${ }^{2}$ and Cornelia I. Bargmann ${ }^{3}$ \\ ${ }^{1}$ Department of Molecular Biosciences, University of Kansas, 5049 Haworth Hall, 1200 Sunnyside Avenue, Lawrence, KS 66045, \\ USA \\ ${ }^{2}$ Howard Hughes Medical Institute, Department of Biology, Massachusetts Institute of Technology, 77 Massachusetts Avenue, \\ Cambridge, MA 02139, USA \\ ${ }^{3}$ Howard Hughes Medical Institute, Department of Anatomy Box 0452, University of California, San Francisco, CA 94143, USA \\ *These authors contributed equally to this work \\ ¥Author for correspondence (e-mail: erikl@ku.edu) \\ Accepted 21 August 2001
}

\section{SUMMARY}

The Caenorhabditis elegans genome contains three rac-like genes, ced-10, mig-2, and rac-2. We report that ced-10, mig2 and $r a c-2$ act redundantly in axon pathfinding: inactivating one gene had little effect, but inactivating two or more genes perturbed both axon outgrowth and guidance. mig-2 and ced-10 also have redundant functions in some cell migrations. By contrast, ced-10 is uniquely required for cell-corpse phagocytosis, and mig-2 and rac-2 have only subtle roles in this process. Rac activators are also used differentially. The UNC-73 Trio Rac GTP exchange factor affected all Rac pathways in axon pathfinding and cell migration but did not affect cell-corpse phagocytosis. CED-5 DOCK180, which acts with CED-10 Rac in cell-corpse phagocytosis, acted with MIG-2 but not CED-10 in axon pathfinding. Thus, distinct regulatory proteins modulate Rac activation and function in different developmental processes.

Key words: C. elegans, Rac, ced-10, mig-2, rac-2, Axon pathfinding, Cell migration, Phagocytosis

\section{INTRODUCTION}

Small GTPases of the Rho family (Rho, Rac, and Cdc42) are key regulators of the actin cytoskeleton and cell-shape changes (Hall, 1998; Zigmond, 1996). Like other small GTPases, Rhofamily GTPases cycle between a GTP-bound signaling state and a GDP-bound inactive state. GTPase activating proteins (GAPs) facilitate GTPase activity leading to the inactive state, and GTP exchange factors (GEFs) stimulate the exchange of GTP for GDP, leading to the active state (Kaibuchi et al., 1999). Both in cultured cells and in developing animals, Rho-family GTPase activity is regulated by extracellular signals, presumably via altered GAP and GEF activity.

During axon pathfinding in the developing nervous system, growth cones, sensory-motile structures at the distal tips of extending axons, respond to extracellular guidance cues by modulating their cytoskeletons and altering their directions of outgrowth (Letourneau, 1996; Tessier-Lavigne and Goodman, 1996). Several guidance receptors and their ligands have been identified (Chisholm and Tessier-Lavigne, 1999), but the pathways that integrate multiple guidance cues and couple receptors to the cytoskeleton remain mysterious. Genetic evidence suggests that Rac GTPases are important in axon growth and guidance. Dominant-negative forms of Rac proteins perturb axon and dendrite development in Drosophila melanogaster and mouse (Luo et al., 1994; Luo et al., 1996).
Gain-of-function (GF) Rac proteins also perturb axon guidance in Drosophila (Luo et al., 1994), and a GF form of the Caenorhabditis elegans Rac-related protein MIG-2 disrupts both cell migration and axon guidance (Zipkin et al., 1997).

Although GF Rac mutants can have powerful effects on axon guidance, it is unclear how Racs normally contribute to axon pathfinding in vivo. Loss-of-function (LF) of individual Rac genes has been analyzed in $C$. elegans, which has three rac genes: mig-2 (a divergent Rac) (Zipkin et al., 1997), ced-10 (Reddien and Horvitz, 2000) and rac-2. mig-2(lf) alleles cause defects in the migrations of the Q neuroblast cells (Zipkin et al., 1997) but cause no apparent axon defects, whereas mig$2(g f)$ alleles cause striking HSN axon defects. Thus, it is unclear whether MIG-2, another Rac, or some other GTPase is normally used in HSN axon guidance. ced-10(lf) alleles cause defective engulfment of cell corpses after programmed cell death and defective migration of the distal tip cells (DTCs) (Reddien and Horvitz, 2000). Apoptotic cell phagocytosis, like growth cone outgrowth, requires modulation of the actin cytoskeleton in response to extracellular cues to produce cellular extensions used for engulfment (Platt et al., 1998). rac2 has not been studied.

Genetic analyses have also identified several regulatory pathways affecting Rho GTPases. C. elegans UNC-73, a Dbl homology Rac-GEF (DH-GEF) protein related to mammalian Trio, is required for normal cell migration, axon outgrowth, and 
axon guidance (Steven et al., 1998). Genetic interactions between unc-73 and mig-2 suggest related functions for these genes in cell and nuclear migration (Zipkin et al., 1997). Drosophila Trio also affects axon pathfinding and acts as a GEF for Racs and MIG-2-related proteins (Awasaki et al., 2000; Bateman et al., 2000; Liebl et al., 2000; Newsome et al., 2000). Genetic interactions between Drosophila trio and Racl suggest that Trio and Rac1 might act together in axon guidance (Newsome et al., 2000).

During apoptotic cell phagocytosis in C. elegans, CED-10 Rac cooperates with CED-2 CrkII, an SH2-SH3-SH3 adaptor protein, and CED-5 DOCK180 (Reddien and Horvitz, 2000; Wu and Horvitz, 1998). CED-5 DOCK180 functions upstream of CED-10 Rac for phagocytosis (Reddien and Horvitz, 2000), and mammalian DOCK180 can increase the amount of GTPbound Rac1 in cell culture (Kiyokawa et al., 1998; Nolan et al., 1998); DOCK180 probably functions as a Rac activator. Myoblast city, a DOCK180-like molecule, acts in myoblast fusion in Drosophila, a process that is sensitive to gain-offunction and dominant-negative Rac activity (Luo et al., 1994; Nolan et al., 1998).

How metazoa use multiple Racs and Rac regulators to control specific developmental processes is unknown. In this study we use loss-of-function analysis of the three $C$. elegans Rac genes to analyze the roles of Rac proteins in axon pathfinding, cell migration and apoptotic cell phagocytosis in vivo.

\section{MATERIALS AND METHODS}

\section{General genetic methods}

Nematodes were cultured by standard techniques (Brenner, 1974; Sulston and Hodgkin, 1988). All experiments were performed at $20^{\circ} \mathrm{C}$. The following mutations were used: LGI, unc-73(e936, gm40, rh40), kyIs8[ceh-23::gfp, lin-15(+)]; LGIII, juIs73[unc-25::gfp]; LGIV, dpy-9(e12), ced-2(n1994, e1752), ced-5(n1812, n2098, n2002), ced-10(n1993, n3246, n3417), dpy-13(e184), kyIs5 [ceh-23::gfp, lin15(+)]; LGV, unc-76(e911); LGX, mig-2(mu28, rh17, gm38 mu133), lin-15(n765), kyIs4[ceh-23::gfp, lin-15(+)]. ced-10(n3417) was isolated by screening a library of ethyl methanesulfonate-induced deletions with PCR as described previously (Jansen et al., 1997). ced10(n3417) lacks exons two and three (from 666 bp 3' of the ced-10 ATG, within intron two, to 1637 bp 3' of the ced-10 ATG, within intron three) of the ced-10 locus, and is predicted to result in the expression of only the first 35 amino acids of CED-10. Germline transformation of nematodes was performed by standard techniques (Mello and Fire, 1995), using lin-15(n765) mutants and lin-15(+) DNA (Clark et al., 1994) as a marker for co-transformation unless otherwise noted. Extrachromosomal arrays were integrated into the genome using trimethylpsoralen/UV mutagenesis (Anderson, 1995) and standard techniques (Mello and Fire, 1995). RNAi was performed by dsRNA injection $(1 \mu \mathrm{g} / \mu \mathrm{l})$ into the body cavity or gonad as described (Fire et al., 1998).

\section{Analysis of CAN and D class motor axon pathfinding and CAN cell migration}

Axons and cell bodies were scored using fluorescence microscopy in living young adult animals that harbored transgenes driving the expression of the green fluorescent protein (GFP) (Chalfie et al., 1994). The ceh-23::gfp transgene (Forrester et al., 1998) was used to score the CAN neuron. A posterior CAN axon was scored as mutant if, because of premature termination or misguidance, the axon failed to extend further than half the distance between the vulva and the phasmid neurons in the tail (approximately to the region of the postdeirid ganglion). CAN cell migration was scored as mutant if the CAN cell body was greater than two CAN cell body-widths from the vulva. Animals harboring a ceh-10::gfp transgene (lqEx44, kindly provided by X. Lu) (injected at $1 \mathrm{ng} / \mu \mathrm{l}$ ) were used to obtain the images of CAN axons and cell bodies in Fig. 2. An unc-25::gfp integrated transgene (juIs73, kindly provided by Y. Jin) was used to score the VD and DD motoneurons. Independence of CAN cell migration and CAN axon pathfinding defects was determined by Chisquare $\left(\chi^{2}\right)$ analysis. Four genotypes were analyzed with one degree of freedom: mig-2(mu28); ced-10(n1993M+), $\chi^{2}=0.34, P=0.56$; unc$73($ rh $40 M+), \chi^{2}=0.44, P=0.51 ;$ mig-2(mu28); rac-2(RNAi), $\chi^{2}=0.84$, $P=0.36$; and $c e d-5(n 1812)$; ced-10(n1993), $\chi^{2}=0.60, P=0.44$. These $P$ values indicate that CAN cell migration and posterior CAN axon pathfinding are independent events.

\section{Molecular biology}

Standard molecular biological techniques were used (Ausubel et al., 1987; Sambrook, 1989). Oligonucleotide primer sequences used for PCR are available upon request. The sequences of all coding regions of clones derived using PCR in this work were determined to ensure that no errors were introduced. The full-length mig-2 cDNA was derived from the clone yk344c5 (kindly provided by Y. Kohara). The ced-10 cDNA has been previously described (Reddien and Horvitz, 2000). $g f p$ expression vectors were kindly provided by A. Fire. The ceh-10::gfp construct (kindly provided by X. Lu) consists of the ceh10 promoter (base pairs 7,343-11,461 of cosmid W03A3) fused to $g f p$. The G12V mutation was introduced into the ced-10 cDNA coding region using the Quikchange Site-Directed Mutagenesis System (Stratagene, La Jolla, CA). Plasmids were injected in germline transformation experiments at $5 \mathrm{ng} / \mu \mathrm{l}$. Five independent array-bearing lines were scored with similar results. Fig. 3 shows data from one representative line (lqEx27).

\section{Cell autonomy of ced-10 and mig-2}

A fragment of the ceh-10 promoter (base pairs 10,342-11,461 of cosmid W03A3) caused CAN neuron-specific expression at low levels and was used to drive the expression of the wild-type mig-2 and ced10 cDNAs in the CAN cell. Transgenes consisting of the wild-type mig-2 and ced-10 cDNAs under the control of the ceh-10 promoter fragment were used in germline transformation experiments $(5 \mathrm{ng} / \mu \mathrm{l})$ with str-1::gfp $(30 \mathrm{ng} / \mu \mathrm{l})$ as a co-transformation marker (Troemel et al., 1997). Two independent array-bearing lines of each construct were tested. CAN defects were scored in both array-bearing animals and in non-array-bearing siblings of the same brood.

\section{ced-10 expression pattern}

The ced-10::gfp::ced-10 construct consists of 7335 bp of DNA $5^{\prime}$ to the start codon of the $c e d-10$ start codon $\left(3309 \mathrm{bp} 5^{\prime}\right.$ to the start codon of C09G12.9, a gene immediately $5^{\prime}$ to $c e d-10$ and likely an upstream gene that shares the promoter with ced-10 (Reddien and Horvitz, 2000) fused to the $g f p$-coding region). The ced-10 genomic coding region was fused in-frame with and downstream of the $g f p$ open reading frame. The construct expressing an NLS-GFP under control of the ced-10 promoter was generated by replacing the ced-10::gfpcoding region with an $n l s$ - $g f p$-coding region. Lines expressing GFP::CED-10 were generated by injection of ced-10::gfp::ced-10 with an unc-76-rescuing construct, P76-16B (Bloom and Horvitz, 1997), both at $75 \mathrm{ng} / \mu \mathrm{l}$, into $u n c-76(e 911)$ animals.

\section{Electron microscopy}

Young adult hermaphrodites were fixed in a mixture of $0.8 \%$ glutaraldehyde and $0.8 \% \mathrm{OsO}_{4}$ in $0.1 \mathrm{M}$ cacodylate buffer $(\mathrm{pH} 7.2)$ for 1 hour at $4^{\circ} \mathrm{C}$ in the dark. Worms were cut in this fixative with a razor blade, the head regions discarded and postfixed in $2 \% \mathrm{OsO}_{4}$ in $0.1 \mathrm{M}$ cacodylate buffer overnight at $4^{\circ} \mathrm{C}$. Approximately four posterior regions were then aligned in an agar block, and the agar 
blocks were dehydrated and infiltrated into an Epon-Araldite mixture. Serial sections $(\sim 30 \mathrm{~nm})$ were collected on Pioloform-coated slotted grids. Sections were poststained with $1 \%$ uranyl acetate and Reynolds lead citrate. Sections were viewed using a JEOL 1200EX electron microscope at $80 \mathrm{kV}$. Sections at two levels, $30 \mu \mathrm{m}$ apart in the region between the gonadal reflex and the vulva, from at least eight worms of each genotype were examined. Only sections from animals with tissue integrity and with clear structures were analyzed.

\section{RESULTS}

\section{The C. elegans Rac gene family}

The genome of $C$. elegans contains three predicted rac-like genes and an apparent rac-like pseudogene (Fig. 1) (The $C$. elegans Genome Sequencing Consortium, 1998). At the amino acid level, CED-10 and RAC-2 (K03D3.10) share 83\% identity with human Rac1. MIG-2, a divergent Rac-like protein, is about $65 \%$ identical to CED-10, RAC-2 and human Rac1, and has a unique domain between residues 124 and 144 (Zipkin et al., 1997). MIG-2 also contains a possible N-terminal myristylation/palmitoylation site not found in other Rac GTPases. An apparent Rac-like pseudogene resides immediately $3^{\prime}$ of $\mathrm{rac}-2$. This locus, K03D3.7, which we will refer to as $\mathrm{rac}-3$, is split in the middle of its third exon by sequences resembling a retrotransposon; the predicted RAC-3 polypeptide, which is $98 \%$ identical to RAC-2, lacks five highly-conserved residues found in all Rac molecules (PASFE, amino acids 87-91 in CED-10). We suspect that rac-3 is a nonfunctional locus.

To analyze the in vivo functions of the $C$. elegans Rac-like genes, we studied the phenotypes of animals deficient in the activities of these genes. The mig-2(mu28) mutation is a nonsense allele predicted to be null (Zipkin et al., 1997). mig- 2(mu28) mutants were healthy, viable and fertile. Two existing alleles of ced-10, n1993 and n3246, are both missense mutations (Reddien and Horvitz, 2000). We isolated a deletion allele of ced-10 (see Materials and Methods) and found that animals homozygous for this allele, $n 3417$, generated from ced-10(n3417)/+ parents were healthy, viable and fertile. However, we could not obtain ced-10(n3417) homozygotes that lacked a maternal wild-type contribution of ced-10, because a maternal-effect lethal phenotype was associated with the ced-10(n3417) strain. We were unable to separate this lethality from the ced-10 mutation. To eliminate wild-type maternal ced-10 function, we crossed ced-10(n1993) males with ced-10(n3417) hermaphrodites and studied the ced10(n3417)/ced-10(n1993) progeny, which were viable. We also used RNA-mediated gene interference (RNAi) (Fire et al., 1998) (see Materials and Methods) to perturb both maternal and zygotic ced-10 function. Both ced-10(n3417)/ced10(n1993) animals and ced-10(RNAi) animals were defective in apoptotic cell phagocytosis and DTC migration and pathfinding and generally resembled ced-10(n1993) animals (Fig. 2, Fig. 3, Fig. 4; and data not shown). However, ced10(n1993)/ced-10(n3417) animals displayed subtle defects in CAN axon pathfinding (Fig. 3), indicating that ced-10(n1993) might not be a null allele and that ced-10 might be slightly required for axon pathfinding.

There are no mutations in the $r a c-2 / 3$ locus, so we perturbed its function using RNAi. We used exon 4 of $r a c-2$ for RNAi, because this exon is the least similar at the nucleotide level to mig-2 (55\% identical) and ced-10 (83\% identical). rac-2 and rac-3 are $99 \%$ identical in this region, so $r a c-2(R N A i)$ could also perturb any $r a c-3$ function. We refer to this treatment as $r a c-2 / 3(R N A i) . r a c-2 / 3(R N A i)$ animals were healthy, viable and fertile. They did not display $\mathrm{Q}$ neuroblast migration defects
Fig. 1. The C. elegans Rac gene family. Alignment of the C. elegans Rac-like proteins CED-10 (Genbank Accession, AAF33846), RAC-2 (CAB05247), RAC-3 (CAB05244) and MIG-2 (AAC47729) with human (Hs) Rac1 (NP008839). Gray shading indicates residues that are identical in at least three out of five sequences. The myristylation signal (myr) of MIG-2 and motifs conserved in all five molecules are underlined. The P-loop region interacts with phosphoryl groups of GDP and GTP, the switch regions change conformation upon GDP/GTP exchange, and the C-terminal membrane targeting signal typically results in prenylation (Bourne et al., 1991; Zhang and Casey 1996). The glycine 12 (G12) residue (G16 in MIG-2) that is altered to a valine in constitutively-active alleles of Rho-family GTPases including mig-2(rh17) is indicated by a $\mathrm{V}$ above the alignment. The $\mathrm{G} 12$ residue was altered to a valine in the ced-10(G12V) cDNA construct. A diagram illustrating the identity relationships among the molecules is shown below the alignment.
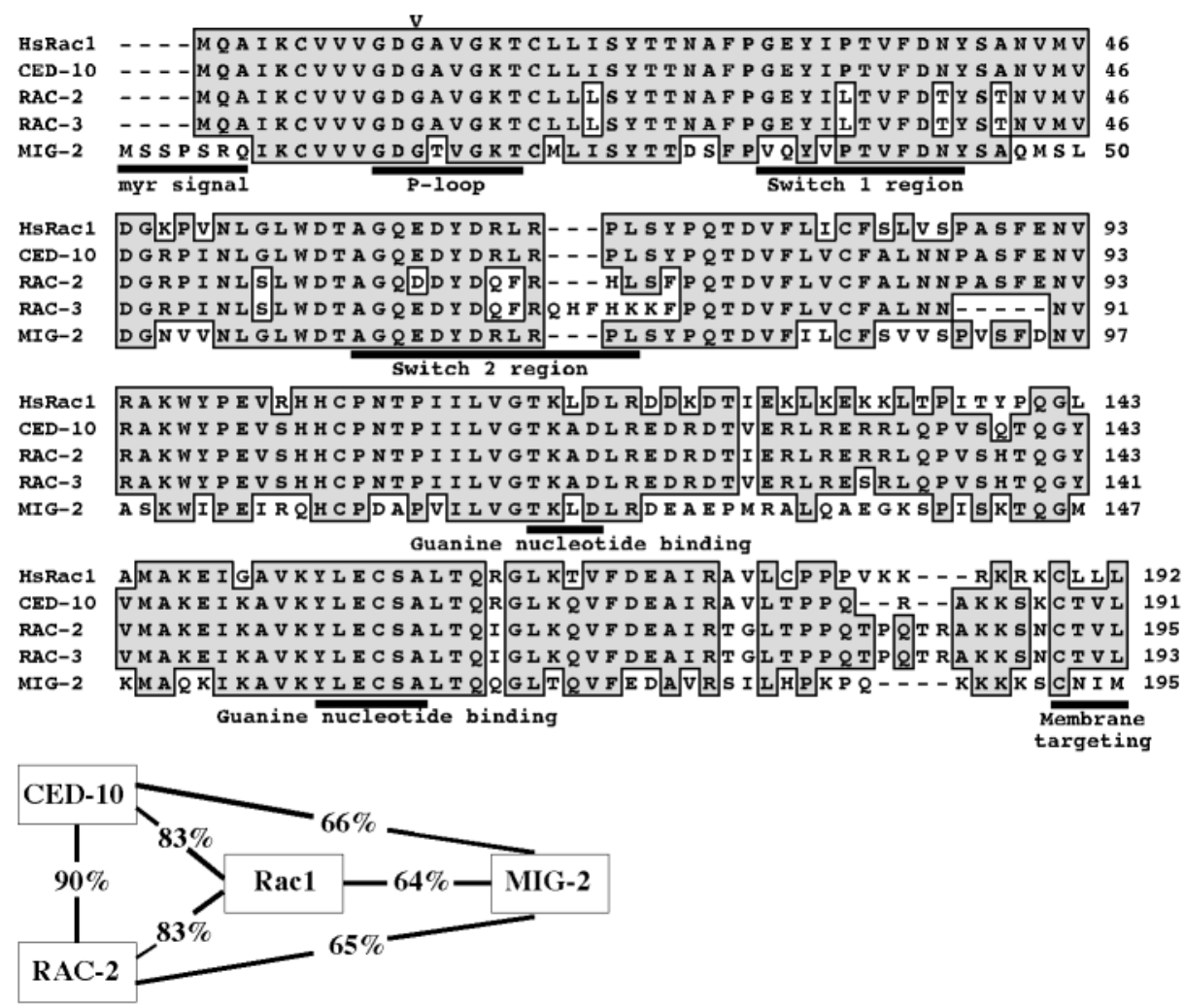
Fig. 2. CAN axon defects in ced-10(M+); mig-2 double mutants. (A) A ced10(n1993)/dpy-13(e184); mig-2(mu28) animal. This animal was non-Unc, nonWit, non-Egl and non-pVul. (B) A ced-10(n1993M+); mig-2(mu28) homozygote. This animal was Unc, Dpy, Wit, Egl and pVul.

(C-G) Fluorescence micrographs of GFP expression from a ceh-10::gfp transgene expressed in the CAN neurons of living animals. (C) The CAN neuron of a wild-type animal is shown. The out-of-focus bright spot near the vulva is the CAN cell body on the other side of the animal. Some head neurons also express ceh-10::gfp. (D) A ced10(n1993M+); mig-2(mu28) double mutant. The posterior CAN axon terminated prematurely. CAN cell position was normal in this animal. (E) The posterior CAN axon of a ced-10(M+); mig-2 double mutant displayed an ectopic axon branch. (F) A posterior CAN axon of a ced-10(n1993M+); mig-2(mu28) double mutant was misguided, turned $180^{\circ}$ and extended anteriorly
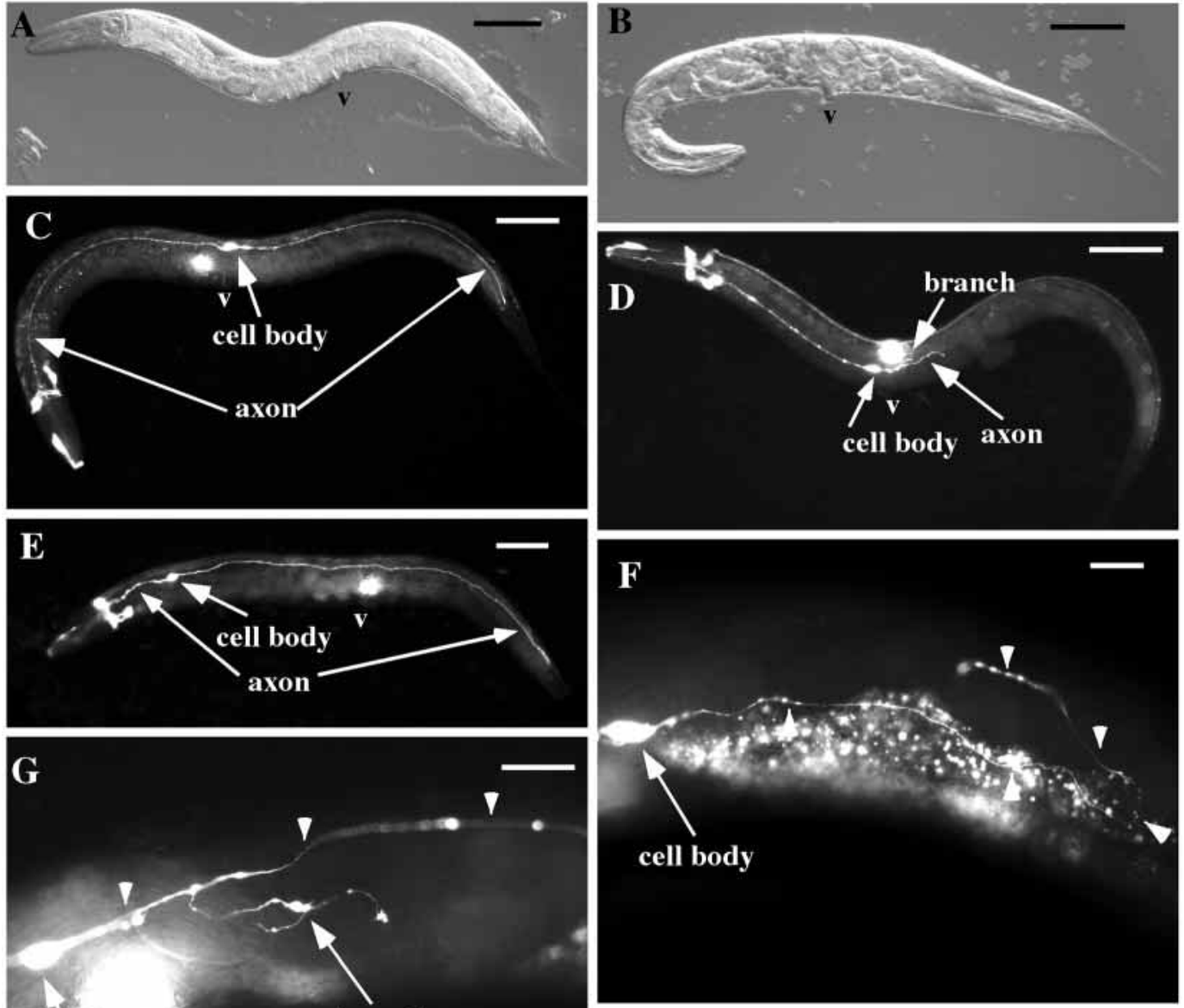

before terminating. Arrowheads trace the trajectory of the axon. The background fluorescence is autofluorescence of the gut. (G) A ced10(n1993M+); mig-2(mu28) double mutant. The CAN cell body failed in its posterior migration. The posterior CAN axon of this animal extended to its normal position in the tail of the animal. The trajectory of the main axon is traced by arrowheads. Anterior, left; dorsal, top. The location of the vulva is indicated by a V. Scale bars: $50 \mu \mathrm{m}$ in A-D,G; $10 \mu \mathrm{m}$ in E,F.

like mig-2(lf) mutants (Zipkin et al., 1997), cell-corpse phagocytosis defects like ced-10(lf) mutants (Reddien and Horvitz, 2000), or DTC-migration defects like mig-2(lf) and ced-10(lf) mutants. Furthermore, rac-2/3(RNAi) animals carrying a $g f$ ::ced-10 reporter had no detectable reduction of GFP::CED-10 expression (data not shown). These results indicate that $r a c-2 / 3$ RNAi did not significantly interfere with the activities of mig-2 and ced-10. Table 1 summarizes the results described below detailing the roles of ced-10, mig-2 and rac-2/3 in CAN axon pathfinding, CAN and distal tip cell migration, and cell-corpse phagocytosis.

\section{ced-10, mig-2 and rac-2/3 function redundantly in CAN axon pathfinding}

We examined mig-2(lf), ced-10(lf), and rac-2/3(RNAi) animals to determine whether these Rac genes are essential for axon pathfinding during development. mig-2, ced-10 and rac2/3(RNAi) animals displayed no apparent defects in the morphologies or positions of the CAN, VD and DD neurons (Fig. 2, Fig. 3, Fig. 4). ced-10(n3417)/ced-10(n1993) animals displayed weak CAN, VD and DD defects in axon morphology, suggesting that a complete lack of ced-10 function might lead to subtle axon pathfinding defects (Fig. 3, Fig. 4).

To investigate the possibility that ced-10 and mig-2 redundantly regulate axon development, we analyzed double loss-of-function ced-10(n1993M+); mig-2(mu28) mutants. (M+ indicates that these animals were homozygous for n1993, but were derived from mothers heterozygous for $n 1993$, therefore retaining maternal ced-10 activity.) ced10(n1993M+); mig-2 double mutants displayed a dumpy (Dpy) body shape, were uncoordinated (Unc), were egglaying defective (Egl), displayed protruding vulvae (pVul) and had a withered tail (Wit), defects not seen in mig-2 or ced-10 single mutants (Fig. 2A,B, and data not shown). These defects suggest that there is considerable redundancy in the functions of ced-10 and mig-2. ced-10(n1993M+); mig-2 double mutants were nearly sterile and generated few progeny, which typically died as embryos or early larvae. Similar results were observed with ced-10(n1993); mig$2(m u 28 \mathrm{M}+)$ mutants and with other allelic combinations of ced-10 and mig-2, such as ced-10(n3246M+); mig-2(mu28) 
Table 1. Summary of defects conferred by Rac gene perturbations

\begin{tabular}{|c|c|c|c|c|c|}
\hline \multirow[b]{2}{*}{ Genotype } & \multicolumn{2}{|c|}{ Axon pathfinding* } & \multicolumn{2}{|c|}{ Cell migration $\neq$} & \multirow[b]{2}{*}{ Phagocytosis ${ }^{\S}$} \\
\hline & CAN & DD/VD & CAN & DTC & \\
\hline Wild type & + & + & + & + & + \\
\hline ced-10(lf) & + & + & + & Moderate & Strong \\
\hline$m i g-2(l f)$ & + & + & + & Strong & + \\
\hline$r a c-2 / 3(R N A i)$ & + & + & + & + & + \\
\hline ced-10(lf); mig-2(lf) & Severe & Severe & Severe & Severe & Strong \\
\hline ced-10(lf); rac-2/3(RNAi) & Moderate & Weak & Strong & Moderate & Severe \\
\hline mig-2(lf); rac-2/3(RNAi) & Moderate & Weak & Severe & Severe & + \\
\hline
\end{tabular}

'+' indicates no defect. 'weak', 'moderate', 'strong' and 'severe' indicate the degrees of defects, where 'severe' indicates the strongest defect observed for a given process.

*CAN axon pathfinding, $\%$ animals defective: 'moderate', more than $20 \%$; 'severe', more than $60 \%$. DD/VD axon pathfinding, $\%$ commissures that failed to reach the dorsal cord: 'weak', approximately $10 \%$; 'severe', approximately $80 \%$.

$\ddagger$ CAN cell migration, $\%$ misplaced cell bodies: 'strong', more than $40 \%$; 'severe’, more than $60 \%$. DTC migration, $\%$ abnormal posterior gonad arms: 'moderate', approximately $20 \%$; 'strong', approximately $30 \%$; 'severe', approximately $40 \%$.

§Phagocytosis of cell corpses, number of persistent corpses in L1 heads: 'strong', 15-20; 'severe', 25-30.

or ced-10(n1993M+); mig-2(gm38 mu133) mutants (data not shown).

A Wit defect is indicative of abnormalities in CAN neuron development (Forrester et al., 1998). We examined CAN neuron morphology in ced-10(M+); mig-2 mutants harboring an integrated ceh-23::gfp transgene, a CAN reporter (Zallen, 1998). The bilateral CAN neurons are generated in the anterior of the embryo and migrate posteriorly to the central region near where the vulva will form (Sulston et al., 1983). The CAN axons extend anteriorly to the head and posteriorly to the tail (White et al., 1986). In contrast to mig-2(mu28), ced10(n1993) and ced-10(n3417)/ced-10(n1993) mutants, ced-
10(n1993M+); mig-2 double mutants displayed severe defects in CAN axon pathfinding: CAN axons displayed premature termination, misguidance, and branching (Fig. 2D-F, Fig. 3). We quantitated these defects for the posterior axons, which were more severely affected (Fig. 3). Defective axons terminated prematurely $(71 \%)$ or became misguided $(29 \%)$, often turning $180^{\circ}$ and extending anteriorly. In addition, $16 \%$ of CAN axons displayed ectopic branching.

Using RNAi, we perturbed $r a c-2 / 3$ function in $m i g-2(m u 28)$ and ced-10(n1993) mutants. In both cases, a weak Wit/Unc/Dpy phenotype as well as CAN axon pathfinding defects were observed (Fig. 3). The penetrance of axon defects

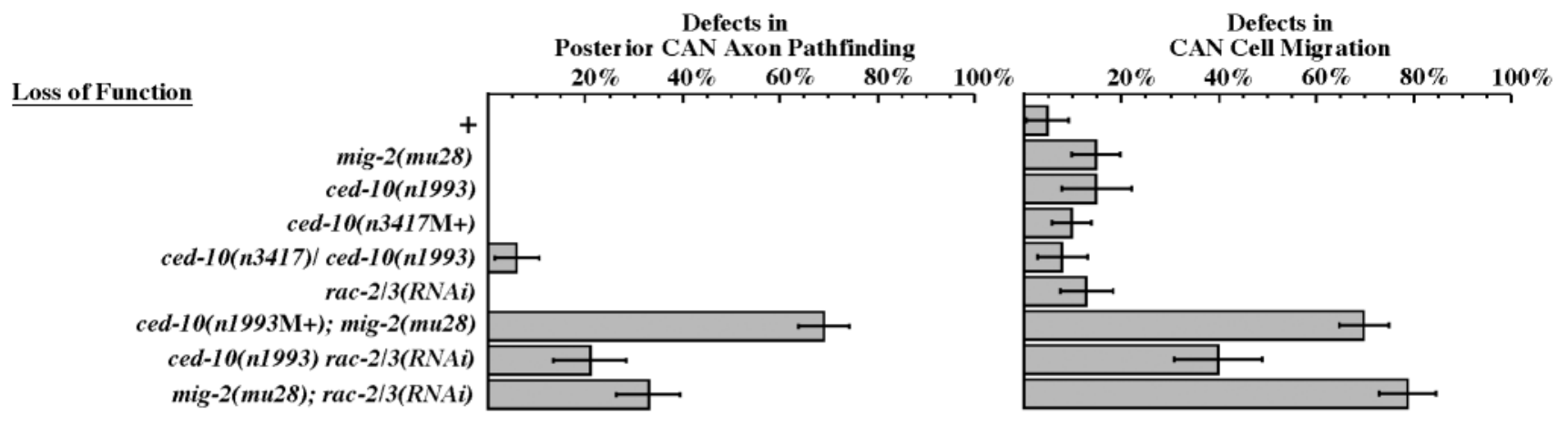

Gain of Function

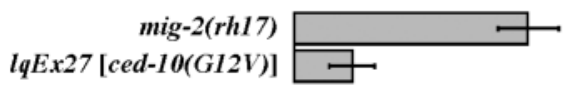

Cell-Autonomous Rescue
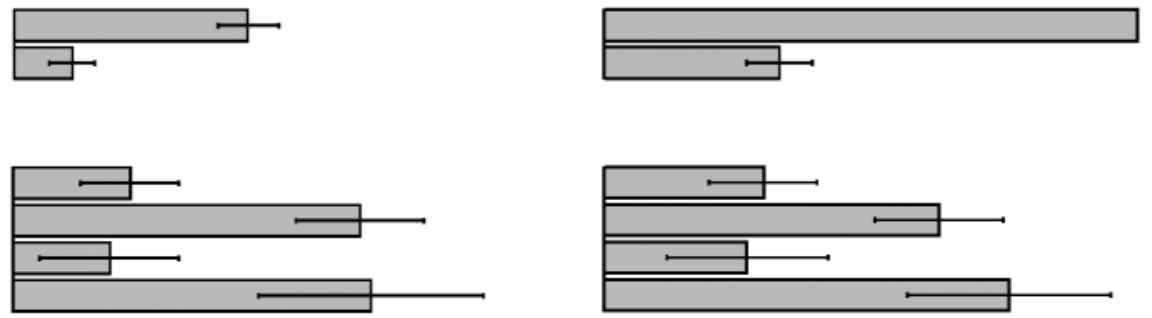

-10(n1993M+); mig-2(mu28); lqEx5 ced-10(n1993M+); mig-2(mu28) sib

ced-10(n1993M+); mig-2(miles) si

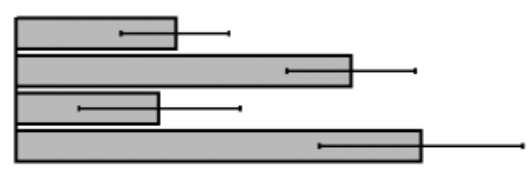

Fig. 3. mig-2, ced-10, and rac-2/3 redundantly and cell-autonomously control CAN axon pathfinding and cell migration. CAN axon pathfinding and cell migration were scored in living animals using ceh-23::gfp integrated transgenes (see Materials and Methods). The percentages of animals displaying defective posterior CAN axon pathfinding and defective CAN cell migration for each genotype are shown. The M+ designation in the genotypes indicates that animals had a wild-type maternal contribution of gene function. ' + ' animals carried the kyIs 8 integrated ceh-23::gfp transgene. lqEx27 is an extrachromosomal array bearing the unc-115 promoter::ced-10(G12V) cDNA transgene. $l q E x 53$ is an array bearing the ceh-10 promoter::mig-2(+) cDNA transgene. lqEx56 is an array bearing the ceh-10 promoter::ced-10(+) cDNA transgene. Genotypes described as 'sib' represent the non-array-bearing siblings from the same brood as array-bearing animals. Error bars define $95 \%$ confidence intervals of the standard error of the proportion. 
in mig-2(mu28); rac-2/3(RNAi) or ced-10(n1993); rac2/3(RNAi) animals was lower than that of ced-10(M+); mig-2 double mutants. Elimination of all three rac functions by rac2/3 RNAi of ced-10(n1993M+); mig-2(mu28) animals led to embryonic and early larval lethality with severe morphological defects, including the Unc, Dpy, Wit phenotype and lumpy body shape (data not shown). We were unable to reliably score CAN axons in these animals. These results suggest that ced10, mig-2 and rac-2/3 have redundant activities in axon pathfinding and viability, and these roles are only apparent when at least two Rac genes are inactivated.

\section{Gain-of-function alleles of $\mathbf{m i g}-2$ and $c e d-10$ disrupt CAN axon guidance and cell migration}

How do defects in axon guidance caused by Rac gain-offunction mutations compare with those caused by Rac lossof-function mutations? The dominant activating allele mig2(rh17) caused defects in CAN axon pathfinding similar to the ced-10(M+); mig-2 double loss-of-function mutant (Zipkin et al., 1997). The mig-2(rh17) mutation might interfere with both mig-2 and ced-10 function in axon pathfinding. To compare the functions of activated mig-2 and activated ced-10, a ced-10 cDNA with a glycine 12 to valine mutation $(\mathrm{G} 12 \mathrm{~V}$; the residue equivalent to that affected in mig-2(rh17)), which should constitutively activate CED-10 (Fig. 1A) (Bourne, 1991; Seeburg et al., 1984), was expressed under the control of the neuron-specific unc-115 promoter (Lundquist et al., 1998). The unc-115 promoter is expressed in most if not all neurons during embryogenesis at a time when axon outgrowth is occurring. Animals harboring this transgene were Unc and Wit, and displayed premature CAN axon termination, misguidance and ectopic branching similar to ced-10(M+); mig-2 double mutants and mig-2(rh17) mutants (Fig. 3). Furthermore, both mig-2( $g f)$ (Forrester and Garriga, 1997) and ced-10(gf) mutations perturbed the migration of the CAN cell body, a defect also seen in ced10(M+); mig-2 double mutants. Expression of the unc-115 promoter alone and expression of the wild-type ced-10 cDNA did not cause CAN axon guidance and cell migration defects (data not shown), indicating that the axon guidance and migration errors were caused by the G12V mutation. These results suggest that dominant-activating mig-2 and ced-10 mutations interfere with multiple rac pathways.

\section{ced-10 and mig-2 function redundantly in VD and DD motor axon pathfinding and fasciculation}

We examined the morphology of other axons in ced10(n1993M+); mig-2 double mutants. The 13 VD and six DD GABAergic motoneurons (McIntire et al., 1993) have axons that extend anteriorly in the ventral cord, branch, extend a circumferential commissure to the dorsal nerve cord, branch again and extend longitudinally in the dorsal cord (White et al., 1986). We examined VD and DD axon morphologies using an unc-25::gfp transgene (Jin et al., 1999). ced-10(n1993), ced10(n3417)/ced-10(n1993) and mig-2(mu28) mutants were normal for VD and DD motor axon extension, pathfinding and fasciculation (Fig. 4C, and data not shown). By contrast, ced10(n1993M+); mig-2(mu28) double mutants had severe defects in axon pathfinding (Fig. 4B,C). In wild-type animals, as well as in mig-2 and ced-10 single mutants, an average of approximately 17 commissures reached the dorsal cord. In ced10(n1993M+); mig-2(mu28) double mutants, an average of 3.1 commissures reached the dorsal cord (Fig. 4C). The mutant axons either stopped, were misrouted, or did not leave the ventral nerve cord. Thus, VD/DD guidance and outgrowth both are defective in ced-10(n1993M+); mig-2 double mutants.

In wild-type animals, the GABAergic axons are tightly fasciculated (McIntire et al., 1992). In ced-10(M+); mig-2 double mutants, $27 \%$ of the ventral cord regions between GABAergic cell bodies had defasciculated axons ( $n=155)$ (Fig. 4B), suggesting that Rac GTPase activity is also important for axon fasciculation.

\section{ced-10 and mig-2 act redundantly to affect the gross structure of the $C$. elegans nerve cords}

To examine the ultrastructure of axons and to assess the overall development of the nerve cords, we analyzed single and double mutants by serial section electron microscopy (White et al., 1986). Two fascicles are present in the C. elegans ventral nerve cord (VNC): the right fascicle contains approximately 55 axons and the left fascicle four to five axons. The dorsal nerve cord (DNC) consists of a single axon fascicle containing approximately 15 axons. The ventral and dorsal nerve cords of mig-2, ced-2, ced-5 and ced-10 single mutants were essentially indistinguishable from those of the wild type (Table 2). By contrast, the total axon numbers in the ventral and dorsal nerve cords were significantly reduced in ced-10(n1993M+); mig-2

Table 2. ced-10 and mig-2 act redundantly to control development of the ventral and dorsal nerve cords

\begin{tabular}{|c|c|c|c|c|c|}
\hline \multirow[b]{2}{*}{ Genotype } & \multirow{2}{*}{$\begin{array}{l}\text { Ventral right bundle } \\
\text { axons } \pm \text { s.d. (range)* }\end{array}$} & \multirow{2}{*}{$\begin{array}{l}\text { Ventral left bundle } \\
\text { axons } \pm \text { s.d. (range)* }\end{array}$} & \multirow{2}{*}{$\begin{array}{c}\text { Dorsal } \\
\text { axons } \pm \text { s.d. (range)* }\end{array}$} & \multicolumn{2}{|c|}{$\begin{array}{c}\text { Average } \% \text { of } \\
\text { defasciculating axons }\end{array}$} \\
\hline & & & & Dorsal & Ventral \\
\hline Wild type & $52.8 \pm 3.4(48-62) n=23$ & $4.8 \pm 0.8(4-7) n=22$ & $15.6 \pm 2.4(11-20) n=24$ & $4.2 \%$ & $0.6 \%$ \\
\hline ced-2(n1994) & $49.8 \pm 4.5(44-61) n=19$ & $4.3 \pm 1.6(0-6) n=20$ & $13.9 \pm 1.6(10-17) n=20$ & $0.7 \%$ & $0.8 \%$ \\
\hline ced-5(n1812) & $50.5 \pm 3.2(44-55) n=18$ & $5.2 \pm 1.5(2-8) n=17$ & $16.1 \pm 2.2(11-20) n=17$ & $1.5 \%$ & $0.9 \%$ \\
\hline ced-10(n1993) & $50.0 \pm 4.4(42-58) n=35$ & $4.2 \pm 2.0(1-9) n=35$ & $13.1 \pm 3.2(0-19) n=35$ & $5.8 \%$ & $0.5 \%$ \\
\hline ced-10(n1993)/ced-10(n3417) & $52.6 \pm 2.6(48-56) n=7$ & $2.6 \pm 1.0(1-4) n=7$ & $12.8 \pm 3.7(9-19) n=8$ & $12.7 \%$ & $5.4 \%$ \\
\hline$m i g-2(m u 28)$ & $49.1 \pm 3.3(45-56) n=14$ & $4.4 \pm 1.2(2-6) n=14$ & $14.2 \pm 2.0(12-18) n=14$ & $1.0 \%$ & $0.3 \%$ \\
\hline ced-2(n1994); mig-2(mu28) & $51.9 \pm 3.4(44-59) n=17$ & $5.0 \pm 1.6(3-9) n=16$ & $12.9 \pm 2.0(10-19) n=17$ & $3.2 \%$ & $0.0 \%$ \\
\hline ced-5(n1812); mig-2(mu28) & $51.9 \pm 3.7(46-58) n=18$ & $4.5 \pm 1.0(2-6) n=17$ & $15.2 \pm 2.3(11-20) n=19$ & $3.1 \%$ & $0.3 \%$ \\
\hline ced-10(n1993M+); mig-2(mu28) & $32.7 \pm 7.7(19-46) n=20$ & $2.3 \pm 2.3(0-8) n=20$ & $4.4 \pm 3.6(0-14) n=22$ & $25.8 \%$ & $6.3 \%$ \\
\hline
\end{tabular}

We cut and examined ultrastructurally two different positions in each worm at a distance of $30 \mu \mathrm{m}$ apart (within a region between the gonadal relex and the vulva). At least eight worms of each genotype were studied.

* Data are average numbers of total axons observed from the total number of positions analyzed ( $n=$ total number of positions).

¥Data are percentages of the total number of axons/position that were separate from the main fascicles. 
A

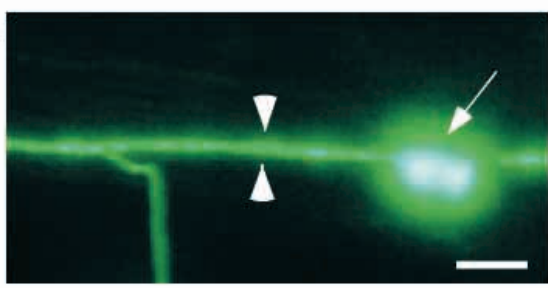

B

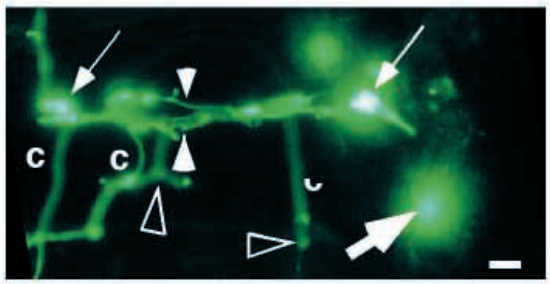

D

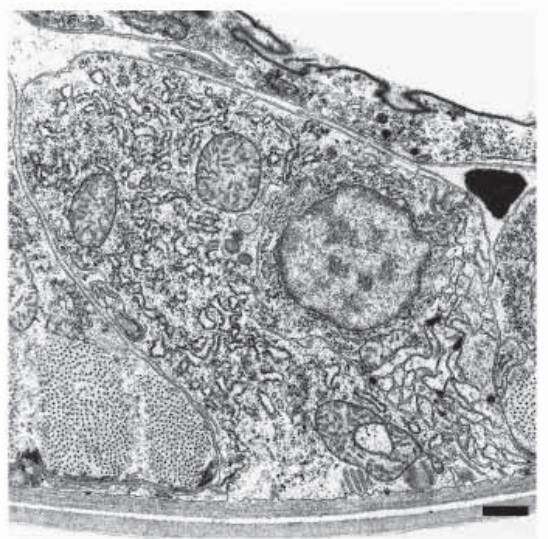

$\mathbf{F}$

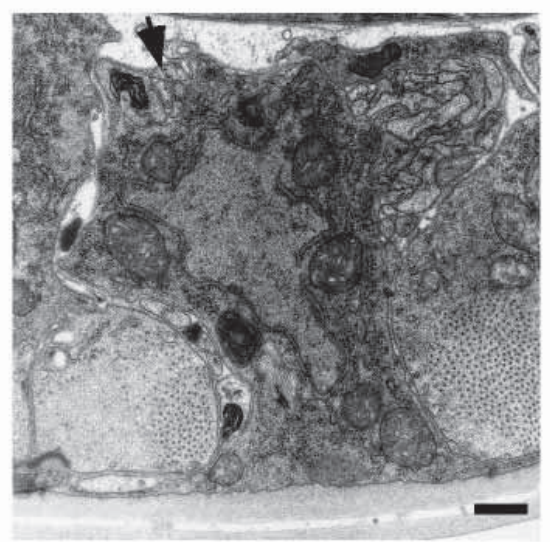

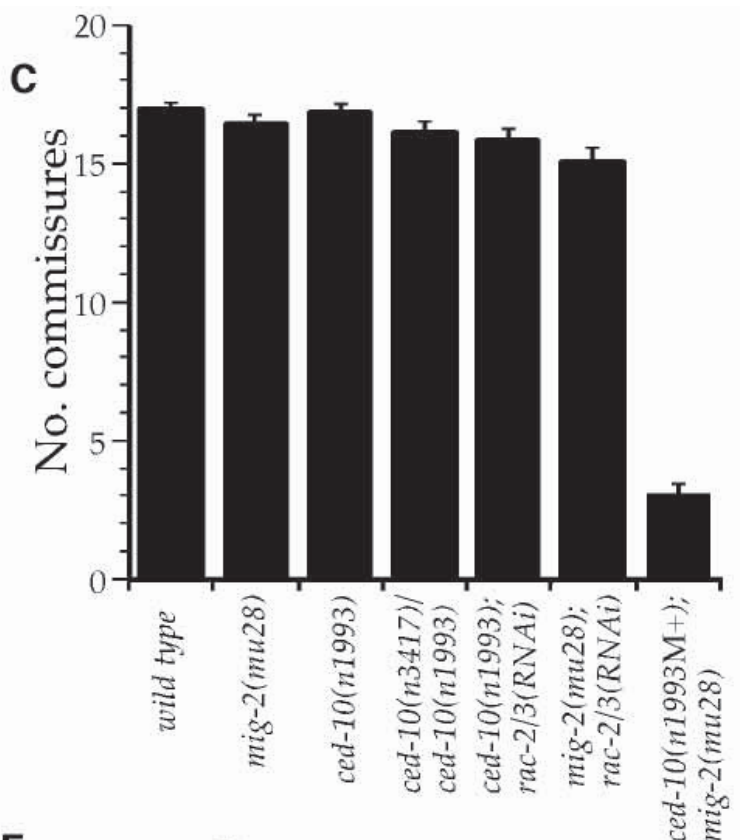

E

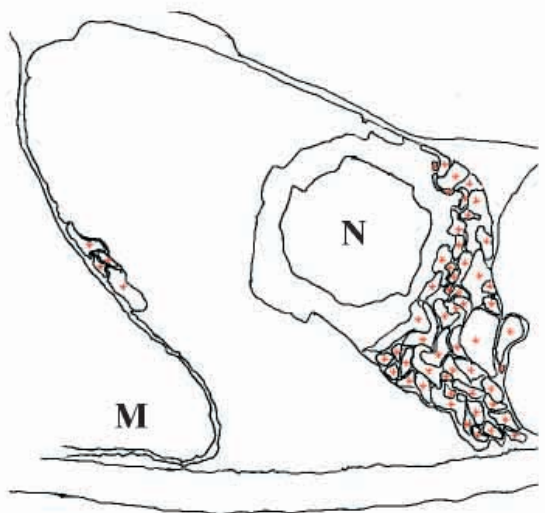

G

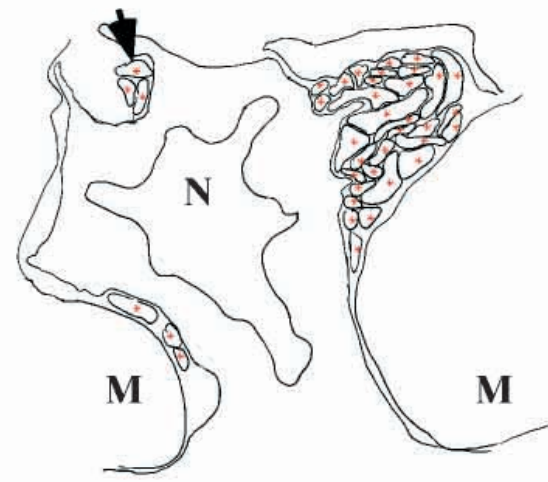

Fig. 4. mig-2 and ced-10 redundantly control the development of the dorsal and ventral nerve cords and D-class motor axon pathfinding. (A,B) Ventral neurons expressing an unc-25::gfp reporter. Anterior is left; the left side of each animal is upwards. Scale bars: $10 \mu \mathrm{m}$. (A) The D class neurons in the ventral cord of a wild-type animal displayed normal fasciculation, cell body positions and commissure extensions. Arrow, cell bodies; arrowheads, ventral cord fascicle; c, commissure. (B) D class neurons in a ced-10(n1993M+); mig-2(mu28) animal. Black arrowheads, terminated and branched axons attempting to form commissures; white arrowheads, defasciculated ventral cord; arrows, D class motoneuron cell bodies. Thick arrow, cell body displaced from the ventral cord. (C) The average number of commissures that reached the dorsal cord was determined from 20 animals for wild type and mutant. Error bars represent standard errors of the mean. (D) An electron micrograph of a wild-type ventral cord. There are 52 axons in the right fascicle and four axons in the left fascicle. Scale bar: $500 \mathrm{~nm}$. (F) An electron micrograph of the ventral cord of a ced-10(n1993M+); mig-2(mu28) double mutant. There are 32 axons in the right fascicle and three axons in the left fascicle. The arrow indicates three axons separated from the main fascicles. Scale bar: $500 \mathrm{~nm}$. (E,G) Tracings of electron micrographs in D,F, respectively. N, nucleus. M, muscle. Red asterisks, axons. 
double mutants, suggesting either guidance defects or premature termination of multiple classes of axons; in addition, one or more axons frequently defasciculated from the main bundles (Fig. 4D-G and Table 2). The ultrastructure of the individual axons was superficially normal. These results demonstrate that CED-10 and MIG-2 Rac-like GTPases are important for the development of many classes of axons.

In summary, axons growing dorsally (VD/DD), anteriorly $(\mathrm{CAN})$, or posteriorly (CAN) were abnormal in ced10(n1993M+); mig-2 double mutants and, to a lesser degree, in ced-10(n1993); rac-2/3(RNAi) and mig-2(mu28); rac$2 / 3(R N A i)$ animals. We conclude that redundant functions of ced-10 and mig-2 are central for axon outgrowth, guidance and fasciculation in $C$. elegans, and that $\mathrm{rac}-2 / 3$ also plays a role in axon guidance.

\section{ced-10 and mig-2 act redundantly in CAN cell migration but are separately required for distal tip cell migration}

Cell migration and axon pathfinding are regulated by many of the same guidance cues and cytoskeletal proteins (Branda and Stern, 1999). As mig-2(gf) (Forrester and Garriga, 1997) and ced-10(gf) mutations cause CAN cell migration defects, we asked whether loss-of-function rac mutations affect this migration. mig-2(lf) and ced-10(lf) single mutants showed no CAN cell migration defects, whereas the ced-10(M+); mig-2 double mutants displayed a strong defect in CAN cell migration (Fig. 2G, Fig. 3). CAN cell bodies were located anterior to the vulva in about $70 \%$ of ced-10(n1993M+); mig2 mutants. If misplaced CAN cell bodies caused CAN axon pathfinding defects, then mutations affecting CAN cell migration might indirectly affect CAN axons. We found the CAN axon pathfinding and cell migration defects were phenotypically and statistically independent of one another (Fig. 2D,G; Materials and Methods). Thus, mig-2 and ced-10 act redundantly in both CAN cell migration and CAN axon pathfinding. We also observed CAN cell migration defects when $\mathrm{rac}-2 / 3$ activity was reduced in either a mig-2 or a $\mathrm{ced}$ 10 mutant (Fig. 3). The CAN cell migration defect was much more severe in mig-2(mu28); rac-2/3(RNAi) animals than in ced-10(n1993); rac-2/3(RNAi) animals. These results indicate that mig-2, ced-10 and rac-2/3 can all act in CAN cell migration.

$12 \%$ of GABAergic cell bodies were laterally displaced along the body wall in ced-10(n1993M+); mig-2(mu28) animals (Fig. 4), a defect not seen in either single mutant (data not shown). This observation suggests a defect in the ventral migrations of the nuclei of the P ectoblasts, the progenitors of the VD motoneurons (Sulston and Horvitz, 1977).

The bilobed gonad of an adult $C$. elegans hermaphrodite is formed by the migrations of the two distal tip cells (DTCs) during larval development (Kimble and Hirsh, 1979). One DTC migrates anteriorly and one migrates posteriorly from the ventral gonadal primordium near the midzone of the animal; both turn dorsally, reverse their direction, and migrate back towards the animal midzone. Whereas the DTCs typically migrate to the midbody in wild type, they frequently reverse their direction of migration in ced-2, ced-5 and ced10 mutants, creating an extra turn in the gonad arms (Reddien and Horvitz, 2000). We found that mig-2(lf) mutants but not rac-2/3(RNAi) animals have a DTC migration-defective
Table 3. ced-2, ced-5, ced-10, mig-2 and unc-73 control the migrations of the gonadal distal tip cells

\begin{tabular}{lcc}
\hline \multicolumn{1}{c}{ Wild type* } & & \\
\hline
\end{tabular}

Posterior gonadal arms were scored in young adults using Nomarski microscopy. Similar results were obtained scoring anterior arms (not shown).

*Diagram of a wild-type posterior gonad arm. Anterior is left, dorsal is upwards. The distal tip cell is shown in black.

† Gonadal arms in which the distal tip cell failed to migrate or stopped migrating or in which loose germ cells were found in place of an intact structure were categorized as abnormal in distal tip cell movement. Loose germ cells could result from germ cell proliferation in a 'short' gonad or could reflect defects in gonadal structure.

$\S$ Gonadal arms with extra turns or that split were categorized as abnormal in DTC pathfinding. Only those gonad arms that were normal in the extent of DTC movement were scored.

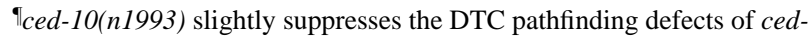
$5(n 1812)$.

phenotype similar to that of ced-2, ced-5 and ced-10 mutants (Table 3). mig-2(gf) mutants have only very subtle DTC defects. ced-10(n1993M+); mig-2 double mutants exhibited a more severe defect in DTC movement compared with the single mutants but did not have a significant increase in the frequency of DTC-pathfinding defects, i.e. in ced-10(M+); mig-2 animals with gonads normal in length, the DTCs had pathfinding defects (extra turns) at a frequency similar to that of the single mutants. Thus, ced-10 and mig-2 are separately required for normal DTC guidance, but might have partially redundant functions in DTC movement. Interestingly, in DTC migration, mig-2(gf) was less severe than mig-2(lf) or ced10(lf) mutations, suggesting that precise regulation of Rac function is not essential for DTC migration.

\section{ced-10 is the primary rac that acts in the phagocytosis of apoptotic cells}

To determine if mig-2 and $\mathrm{rac}-2 / 3$ function similarly to ced-10 in the phagocytosis of apoptotic cells, we examined mig-2 mutants and rac-2/3(RNAi) animals for the presence of unengulfed cell corpses using Nomarski optics. No detectable defects in cell-corpse engulfment were seen in mig-2(lf) or 
Table 4. Phagocytosis of apoptotic cells is primarily controlled by ced-10 Rac and independently of unc-73

\begin{tabular}{|c|c|}
\hline Genotype & $\begin{array}{l}\text { Persistent corpses } \\
\quad(\mathrm{L} 1 *)(n \geq 25)\end{array}$ \\
\hline Wild type & $0.0 \pm 0.0$ \\
\hline ced-10(n1993) & $18.2 \pm 3.8$ \\
\hline$m i g-2(m u 28)$ & $0.0 \pm 0.0$ \\
\hline $\operatorname{mig}-2(\operatorname{rh} 17)$ & $0.0 \pm 0.0$ \\
\hline$r a c-2 / 3$ (RNAi) & $0.1 \pm 0.3$ \\
\hline ced-10(n1993); rac-2/3(RNAi) & $26.2 \pm 4.6$ \\
\hline mig-2(mu28); rac-2/3(RNAi) & $0.1 \pm 0.4$ \\
\hline ced-10(n1993) & $25.1 \pm 4.0$ \\
\hline ced-10(n1993); mig-2(mu28) & $28.0 \pm 4.8$ \\
\hline ced-2(n1994) & $20.3 \pm 3.3$ \\
\hline ced-2(n1994); mig-2(mu28) & $32.0 \pm 3.7$ \\
\hline ced-2(n1994); rac-2/3(RNAi) & $31.3 \pm 3.7$ \\
\hline ced-5(n2098) & $15.4 \pm 4.9$ \\
\hline ced-5(n2098); mig-2(mu28) & $26.7 \pm 4.8$ \\
\hline ced-5(n1812) & $31.0 \pm 3.6$ \\
\hline ced-5(n1812); mig-2(mu28) & $30.5 \pm 5.1$ \\
\hline ced-5(n1812); rac-2/3(RNAi) & $38.5 \pm 5.6$ \\
\hline ced-10(n1993) ced-5(n1812) & $31.6 \pm 4.2$ \\
\hline unc-73(rh40) & $0.0 \pm 0.2$ \\
\hline unc-73(rh40); mig-2(mu28) & $0.1 \pm 0.3$ \\
\hline
\end{tabular}

The numbers of persistent corpses were determined using Nomarski optics. * Newly hatched L1 larvae with four gonadal precursor cells were scored. \$e determined the total numbers of persistent corpses in ced-10(n1993); mig-2(mu28) 3.5-fold embryos rather than L1 larvae because these larvae were often inviable or morphologically abnormal. Therefore, apparent L1 animals were often older than L1 animals of other genotypes. mig-2(gf) mutants, rac-2/3(RNAi), or in mig-2(mu28); rac2/3(RNAi) animals (Table 4). However, rac-2/3(RNAi) enhanced the engulfment defects of ced-2, ced-5 and ced-10 mutants (Table 4). mig-2(lf) enhanced loss-of-function mutations in ced-2 (e1752 and n1994) and ced-5(n2098), but it did not enhance the stronger loss-of-function allele, ced$5(n 1812)$. These results demonstrate that ced-10 has a primary role in phagocytosis, that $r a c-2 / 3$ has a weak redundant role and that mig-2 has a minor role that was revealed only in genetically sensitized backgrounds.

\section{mig-2 and ced-10 can act cell-autonomously in the CAN neurons}

We investigated the expression of ced-10 by generating a gfp::ced-10 fusion transgene that can express a full-length CED-10 molecule with an N-terminal GFP tag from the ced10 promoter (see Materials and Methods) and that can rescue the phagocytosis defect of ced-10(n1993) animals (data not shown). GFP::CED-10 was expressed broadly, perhaps in all cells, including neurons (CANs, VDs and DDs), engulfing cell types (including the hypodermis, intestine and pharynx) and the distal tip cells (Fig. 5). We detected strong fluorescence within the axons of the nerve ring. The expression pattern of mig-2 has been previously determined (Zipkin et al., 1997) and is similar to that of ced-10, except that mig-2 expression was not observed in the intestine. The GFP::CED-10 fusion protein accumulated at the plasma membrane, demonstrating that,
Fig. 5. ced-10 is expressed broadly. Anterior, left; dorsal, top. Scale bars: $5 \mu \mathrm{m}$ in A; 2.5 $\mu \mathrm{m}$ in $\mathrm{B}, \mathrm{C} ; 5 \mu \mathrm{m}$ in D,E. (A) A mid-L1-stage larva showing GFP::CED-10 expression in all cells examined, including the pharynx, axons of the nerve ring, and neurons along the ventral nerve cord (vnc), where the GABAergic D-class motoneurons reside. GFP::CED-10 localized to the plasma membrane in vnc neuron cell bodies. (B) A different focal plane of the animal in A showing expression of GFP::CED-10 in the hypodermis. The hypodermal seam cells (V cells) are noted with arrows. GFP::CED-10 accumulated at the plasma membrane in these cells. (C) An L2 larva with plasma membrane accumulation of GFP::CED-10 in vnc motoneuron cell bodies. Intestinal expression is also shown. (D) GFP::CED-10 accumulation at the plasma membrane of the CAN neuron cell body in an adult animal. The fused hypodermal seam syncytium also showed plasma

membrane-localized GFP::CED-10. (E) An L4 larva with expression of GFP::CED-10 in the posterior distal tip cell of the developing gonad.
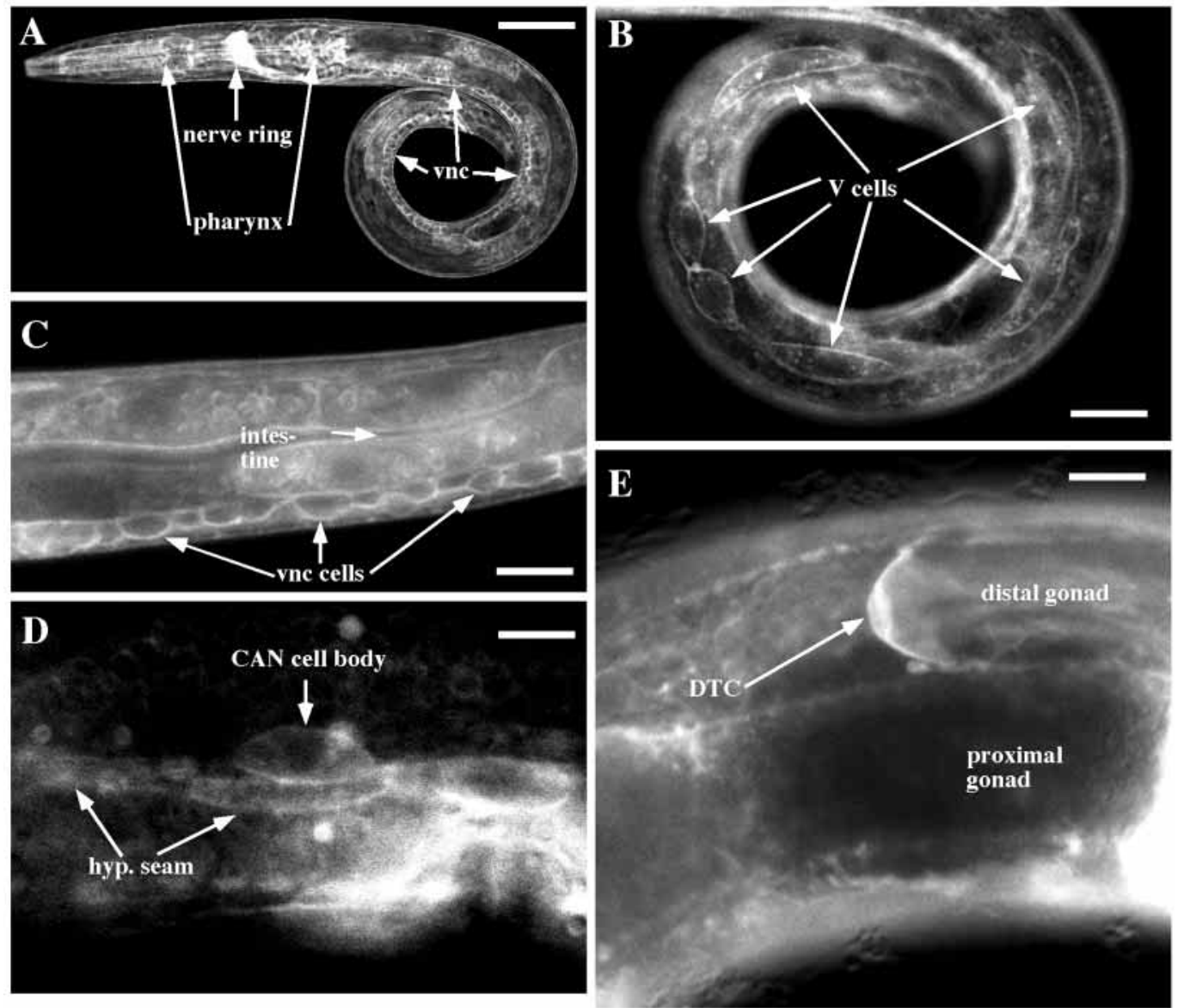
similar to other Ras-family GTPases, CED-10 is localized to the plasma membrane; this localization was presumably mediated through prenylation at its C-terminal CAAX box (Zhang and Casey, 1996). Expression was first seen in early embryogenesis and continued throughout adulthood in all cell types. Cell type identifications were confirmed by the examination of a nuclear-localized GFP expressed from the ced-10 promoter (data not shown).

mig-2 and ced-10 could redundantly control axon development and cell migration by acting in the same cell, or they might act in different cells, such as a migrating cell and a neighboring cell that provided a substrate for migration. To determine the cellular focus of mig-2 and ced-10 action, we analyzed the abilities of transgenes that express the wild-type mig-2 or ced-10 cDNA specifically in the CAN neurons to rescue the CAN axon pathfinding and CAN cell migration defects of ced-10(M+); mig-2 double mutants. The ceh-10 promoter is expressed in the CAN neurons and displays no detectable expression in neurons or other cells in the vicinity of the CANs or their axons (Svendsen and McGhee, 1995). ceh-10::mig-2 cDNA and ceh-10::ced-10 cDNA transgenes both partially rescued the CAN axon pathfinding and cell migration defects of ced-10(M+); mig-2 double mutants, whereas the non-transgene-bearing siblings of rescued animals were not rescued (Fig. 3). These results indicate that both mig-2 and ced-10 can function cell-autonomously in the CAN cells to mediate axon pathfinding and cell migration.

\section{unc-73 acts with ced-10, mig-2 and rac-2/3 in axon pathfinding and cell migration but does not affect apoptotic cell phagocytosis}

A likely modulator for Racs in axon guidance and cell migration is the dual DH-GEF protein UNC-73/Trio. unc-73 mutants have strong axon outgrowth, axon guidance and cell migration defects (Steven et al., 1998). unc-73 produces multiple transcripts, and all known unc-73 mutations affect only those transcripts that include the first DH-GEF1 domain, a Rac-specific GEF domain. The DH-GEF2 domain, which is spared by unc-73 mutations, might act on Rho (Bellanger et al., 1998; Debant et al., 1996). The C. elegans DH-GEF1 domain acts specifically on Rac (Steven et al., 1998), and Drosophila Trio DH GEF1 domain acts on Drosophila Rac1, Rac2 and the Drosophila MIG-2 counterpart Mtl (MIG-2 like) but not on RhoA, RhoL or Cdc42 (Newsome et al., 2000).

unc-73(rh40), unc-73(e936), and unc-73(gm40) LF mutants displayed moderate posterior CAN axon defects and

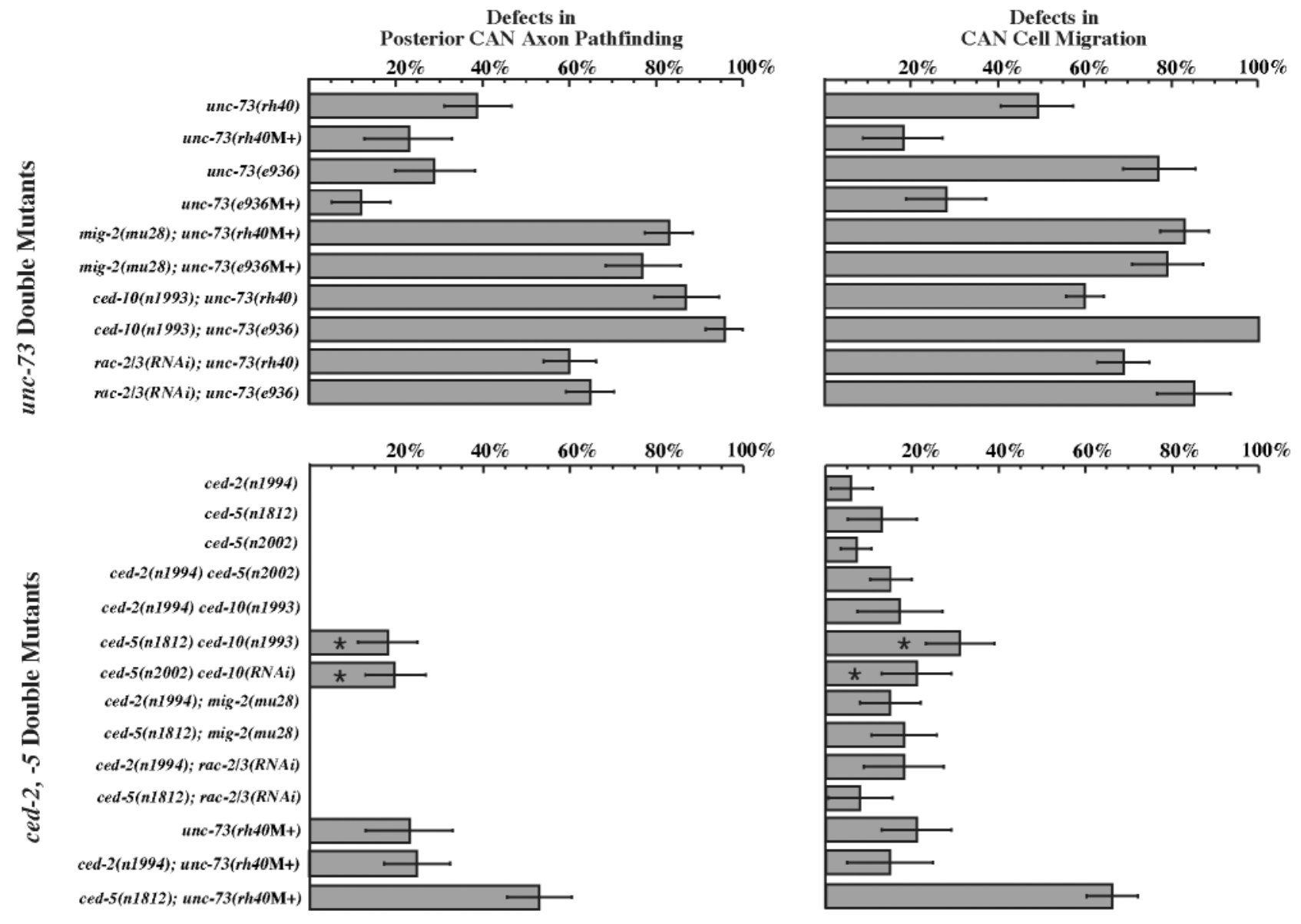

Fig. 6. unc-73 and ced-5 but not ced-2 act with rac genes in CAN axon pathfinding and cell migration. Data are displayed as in Fig. 3 . The CAN axon pathfinding and cell migration defects of ced-5(n1812) ced-10(n1993) and ced-5(n2002) ced-10(RNAi) mutants (marked by asterisks) were significantly more severe than those of $c e d-5$ and $c e d-10$ mutants alone $(P<0.001)$. 
CAN cell migration defects (Fig. 6; data not shown). These defects were enhanced by mig-2(mu28) and ced-10(n1993) mutations, and by rac-2/3(RNAi) (Fig. 6A). These results and the observation that the neuronal defects of unc-73 mutants and $\mathrm{rac}$ gene double mutants were similar lead us to suggest that UNC-73 regulates multiple Rac proteins for axon guidance in vivo.

The CAN cell migration defects of unc-73 mutants were partially rescued by maternally provided wild-type unc-73 (unc-73(M+)), whereas axon guidance and extension were severely compromised in unc-73(M+) animals (Fig. 6). This observation supports the hypothesis that CAN cell migration and CAN axon guidance and outgrowth are separable processes that involve shared molecules.

unc-73 had little effect on Rac functions in non-neuronal cells. unc-73(rh40) mutants had a mild DTC-reversal phenotype similar to that of ced-10 and mig-2 mutants (Table 3 ), essentially no defect in DTC movement (Table 3), and no effect on cell-corpse phagocytosis (Table 4). Animals homozygous for the stronger unc-73(gm40) allele (Forrester and Garriga, 1997) with wild-type maternal unc-73 (gm40 causes maternal-effect lethality) also showed no defects in cell-corpse phagocytosis (data not shown). In addition, we observed no enhancement of defects in phagocytosis (data not shown) or DTC migration (Table 3 ) in animals doubly mutant for unc-73 and ced-2, ced-5, ced-10 or mig-2. Thus, Rac effects on neuronal development can be explained by signaling through $u n c-73$, as the Rac double mutant neuronal phenotype resembles the unc-73 neuronal phenotype. Rac function in non-neuronal tissues is likely to be unc-73independent, as indicated by the observation that $u n c-73$ has no role in cell-corpse phagocytosis.

\section{ced-5 but not ced-2 functions in CAN axon pathfinding and CAN cell migration}

Another candidate Rac regulator is CED-5/DOCK180, which functions with the CED-2/CrkII adaptor and CED-10 in cell corpse phagocytosis (Reddien and Horvitz, 2000). ced2(n1994), ced-5(n1812) and ced-5(n2002), all probably null alleles, displayed no defects in CAN axon development or CAN cell migration (Fig. 6). In contrast to ced-10(M+); mig2 double mutants, in ced-5(n1812); mig-2 and ced-2; mig-2 double mutants, the ventral and dorsal nerve cords were phenotypically normal when examined by electron microscopy (Table 2). Therefore, CED-10 is uncoupled from CED-2 and CED-5 in axonal pathfinding.

Interestingly, ced-5(n1812) ced-10 and ced-5(n2002) ced10(RNAi) animals exhibited synthetic CAN cell migration and CAN axon guidance defects (Fig. 6), and ced-5(n1812) enhanced CAN axon and cell migration defects of unc73(M+). ced-5(n1812); mig-2 double mutants and ced5(n1812) rac-2/3(RNAi) animals did not have CAN cell migration or axon defects (Fig. 6). These results suggest that ced -5 acts redundantly with ced-10 in the mig-2 or $\mathrm{rac}-2 / 3$ branch of the Rac pathway, as eliminating two components of the same branch should have no greater effect than eliminating each alone. No synthetic defects were observed in double mutants of ced-2(n1994) with ced-10(n1993), mig2(mu28), ced-5(n2002) or unc-73(rh40), or rac-2/3(RNAi) (Fig. 6), indicating that ced-2 is probably not involved in CAN axon guidance and CAN cell migration.

\section{DISCUSSION}

Rac GTPases have been implicated in axon pathfinding through the analysis of dominant constitutively active or dominant-negative forms of these proteins (Van Aelst and D'Souza-Schorey, 1997). Previous studies using loss-offunction mutations implicated the C. elegans Rac gene ced-10 in cell migration and apoptotic cell phagocytosis (Reddien and Horvitz, 2000), the C. elegans Rac-like gene mig-2 in Q cell migration (Zipkin et al., 1997), the mouse Racl in gastrulation during embryonic development and cell migration (Sugihara et al., 1998), and the mouse Rac2 gene in a number of neutrophil functions, including cell migration (Roberts et al., 1999). We have used loss-of-function analysis to show that the three $C$. elegans Rac-like genes, ced-10, mig-2 and rac-2/3, have redundant functions in axon guidance, outgrowth, and fasciculation (Table 1).

Our results explain why loss-of-function Rac mutations are not as severe as dominant constitutively-active or dominantnegative alleles. We found that the axon guidance and cell migration defects caused by dominant constitutively active alleles of either mig- 2 or ced-10 resembled the phenotype of the ced-10; mig-2 loss-of-function double mutant, suggesting that regulated Rac activity is essential for axon pathfinding and that the disregulation by constitutive activation of one Rac is as disruptive as a loss of function of multiple Racs. Constitutive activation of a single Rac protein might lock an entire pathway into an active configuration, eliminating dynamic function; a single activated Rac protein might trigger an inhibitory feedback mechanism that attenuates all Rac signaling; or an activated Rac might constitutively bind to and sequester upstream or downstream effectors used by multiple Racs. These results indicate that the effects of constitutively active Rac molecules can be explained by their effects on redundant Rac pathways.

\section{Racs are used differently to control multiple developmental processes}

We present models for the functions of the three C. elegans Rac genes in Fig. 7. In C. elegans, multiple and possibly all axons use redundant Rac proteins to control their development (Table 1, Fig. 7). A central role for Racs in axon motility is consistent with the severe outgrowth defects in unc-73/trio mutants of both C. elegans and Drosophila (Awasaki et al., 2000; Bateman et al., 2000; Liebl et al., 2000; Newsome et al., 2000) and with the axon termination defects caused by dominant-negative Rac mutations in Drosophila (Luo et al., 1994).

In cell migration, the roles of Rac proteins appear to be different in different cell types. ced-10, mig-2 and rac-2/3 act redundantly in CAN cell migration: two of these genes must be inactivated for defects to occur. By contrast, inactivation of either ced-10 or mig-2 led to defects in distal tip cell (DTC) migration. It is possible that ced-10 and mig-2 control distinct essential pathways in the DTCs, such that loss of either Rac can lead to a defect in migration. Alternatively, ced-10 and mig-2 could control a single pathway in the DTCs, with the activities of both genes needed to drive this pathway sufficiently for normal migration. Similarly, ced-10, mig-2 and rac- 2 could control a single pathway in CAN cells, with any two of these Racs sufficient to allow normal cytoskeletal rearrangements. Alternatively, Racs could regulate cell 
Fig. 7. Models for the redundancy of Rac function in axon pathfinding, cell migration, and cell-corpse phagocytosis. Boxes indicate a required gene and broken arrows indicate a subtle function. (A) mig-2 Rac-like, ced-10 Rac and $\mathrm{rac}-2 / 3 \mathrm{Rac}$ act redundantly in CAN axon pathfinding and cell migration. unc-73 Trio acts in all three pathways. ced-5 DOCK180, which acts in parallel with ced-10 Rac, might act with mig-2 Rac-like, $r a c-2 / 3$ Rac or both (indicated by parentheses). ced-2 CrkII is not involved in CAN axon pathfinding. (B) mig-2 Rac-like, ced-10 Rac and rac-2/3 Rac act redundantly in CAN cell migration. mig-2 Rac-like and ced-10 Rac are both necessary for DTC migration and are regulated by unc-73 Trio, ced-2 CrkII and ced-5 DOCK180. rac-2/3 Rac is not necessary for DTC migration and is not shown here. $r a c-2 / 3$ Rac is slightly redundant for cell movement with $\mathrm{mig}$ 2 but not ced-10. (C) ced-10 Rac is the primary $\mathrm{rac}$ involved in phagocytosis, whereas rac-2/3 Rac and mig-2 Raclike have subtle functions seen only in genetically sensitized backgrounds. unc-73 Trio is not involved in phagocytosis.

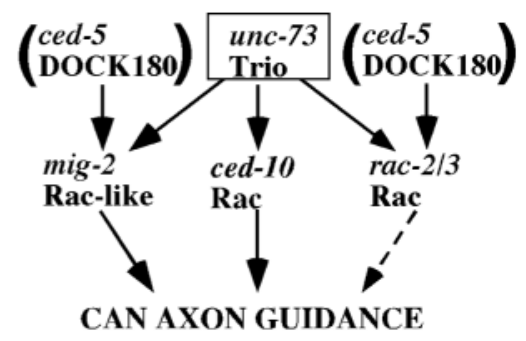

(B)
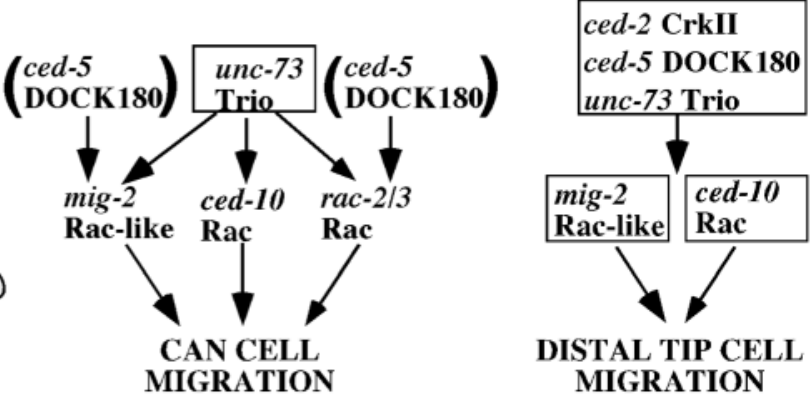

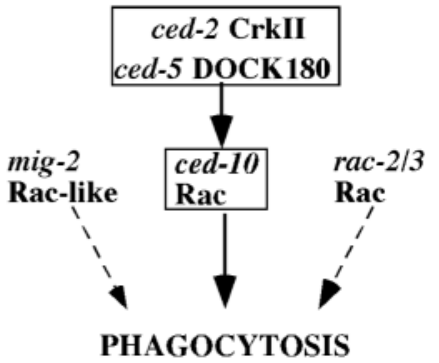

required function migration via distinct and redundant pathways in the CAN cells, an idea supported by the observation that ced-5 acts redundantly with $\mathrm{ced}-10$ but not mig-2 or $\mathrm{rac}-2 / 3$.

Specific expression of either ced-10 or mig- 2 in the CAN cells rescued the ced-10(M+); mig-2 CAN cell migration and axon defects. These results suggest that redundant Rac proteins are required in the same cell for motility and axon pathfinding. The increasing severity of defects in double and triple mutants suggests that complete removal of Rac activity results in a complete failure of axon outgrowth and cell migration.

Other developmental processes preferentially involve individual Racs. Most strikingly, CED-10 is the primary Rac controlling phagocytosis; RAC-2/3 and MIG-2 appear to have only minor roles. ced-10 and mig-2 expression patterns are broad and overlapping (Zipkin et al., 1997) (this work), so this distinction might reflect a difference in the abilities of different Racs to interact with particular regulators or targets.

\section{Distinct regulatory proteins modulate Racs in different developmental processes}

We found that UNC-73 Trio acted with multiple Racs to control axon guidance and cell migration but had no apparent role in Rac-mediated phagocytosis. C. elegans UNC-73 and Drosophila Trio modulate axon guidance and cell migration in vivo and Rac and Mtl (MIG-2 like) activity in vitro (Steven et al., 1998). Mice lacking Trio are inviable and have defects in neural organization (O'Brien et al., 2000). In addition to a Rac GEF domain there are other conserved domains in Trio/UNC73 proteins, including the DH GEF2 Rho GEF (Debant et al., 1996), spectrin repeats, and SH3, Ig, FNIII and pleckstrin homology domains. We found that axon guidance defects conferred by unc-73(rh40), a point mutation in the Rac GEF domain that severely attenuates Rac GEF activity in vitro (Steven et al., 1998), were enhanced by ced-10, mig-2 and rac2. This result suggests either that regions of UNC-73 Trio outside of the Rac GEF domain regulate Rac function or that axon pathfinding involves Rac activators in addition to UNC73 Trio. The latter model is supported by the observation that ced-5 DOCK180 mutation enhances unc-73(rh40) axon pathfinding defects. Alternatively, unc-73(rh40) might not completely eliminate DH-GEF1 activity.

Although CED-2 CrkII and CED-5 DOCK180 act in a pathway with CED-10 Rac during phagocytosis (Reddien and Horvitz, 2000), we found that CED-2 CrkII and CED-5 DOCK180 are uncoupled from CED-10 Rac in axon pathfinding and CAN cell migration: eliminating ced-10 but not ced-2 or ced-5 in a mig-2 mutant background caused CAN defects. These observations demonstrate that CED-10 can be activated differently in distinct developmental processes. If ced-2 or ced-5 does act with ced-10 during axon pathfinding, 
then ced-2 or ced-5 must be redundant with other ced-10 upstream regulators during axon development but not during phagocytosis.

Myoblast City, a Drosophila CED-5 DOCK180-like molecule that regulates muscle cell fusion, has no known role in axon pathfinding (Erickson et al., 1997). We found that while ced-5 single mutants displayed no axon and cell migration defects, synthetic interactions placed ced-5 function parallel to, rather than in conjunction with, ced-10, possibly in a pathway with mig-2 or rac-2/3, in axon pathfinding and CAN migration. Furthermore, ced-2 did not interact with any of these Rac genes in axon guidance. That ced-5 acts with ced10 in phagocytosis and parallel to ced-10 (in the mig- 2 or rac$2 / 3$ pathways) in axon pathfinding and cell migration suggests that Rac activators can differentially affect specific Racs. Therefore, Rac proteins might be components of redundant signaling pathways. This hypothesis is supported by the observation that in phagocytosis $\mathrm{rac}-2 / 3$ acts independently of ced-2 CrkII and ced-5 DOCK180, indicating that RAC-2/3 and CED-10 might interact with different GEFs in phagocytosis. In different cell types these putative Rac pathways could differ. The expression of DOCK180 leads to an increase in GTP-bound Rac in cell culture (Kiyokawa et al., 1998). Our results suggest that DOCK180 might preferentially activate different Racs in different cell types, as CED-5 DOCK180 acts with CED-10 Rac in phagocytosis and might act with MIG-2 Rac-like or RAC-2/3 Rac in axon pathfinding.

We suggest that the use of alternative Rac activators such as UNC-73 Trio and CED-5 DOCK180 might help differentiate the cellular responses to extracellular stimuli, allowing a cell to respond by engulfment, migration, or axon extension depending on the set of activators present. Distinct cues may lead to distinct cellular responses by activating specific Rac activators, such as CED-2 CrkII and CED-5 DOCK180 for phagocytosis and UNC-73 Trio for axon pathfinding.

Multiple Rac activators and Rac pathways might interpret and integrate multiple extracellular signals that act on axon growth cones, migrating cells, and phagocytes. Rho and Ras GTPase signaling pathways can interact with Rac signaling (Bar-Sagi and Hall, 2000). Signals from such non-Rac GTPases could likewise be mediated by distinct Rac pathways.

\section{Rac pathways have both shared and distinct functions}

Our results indicate that Rac proteins can be uniquely required (CED-10 is the only Rac necessary for phagocytosis), redundant (CED-10, MIG-2 and RAC-2/3 are redundantly required for axon pathfinding and CAN cell migration), or multiply required (both CED-10 and MIG-2 are required for proper DTC pathfinding). Differences in expression, localization, physical interactions and biochemical activities could lead to the differences between the in vivo functions of C. elegans Rac proteins. Drosophila has three Rac genes, Rac1 (Harden et al., 1995), Rac2 (Hariharan et al., 1995) and Mtl (Mig-2-like) (Newsome et al., 2000), and humans have at least three, $R A C 1, R A C 2$ and $R A C 3$ (Didsbury et al., 1989; Haataja et al., 1997). Thus, a multigene Rac family might be conserved across species, suggesting that a similar logic in the functions of Rac proteins in cell morphogenesis might also be conserved among many organisms.
We thank M. Herman, R. K. Herman, E. Miska and R. Ranganathan for critical reading of this manuscript. We thank A. Fire for providing $g f p$ plasmids, Y. Jin for the unc-25::gfp construct, X. Lu for the ceh$10: \because g f p$ construct, and J. Zallen for the ceh-23::gfp construct. We thank the Caenorhabditis Genetics Center, J. Culotti and G. Garriga for providing C. elegans strains. We thank members of the Bargmann and Horvitz laboratories for ideas and stimulating discussion. E. A. L was supported by a Damon Runyon-Walter Winchell Cancer Research Fund Fellowship (DRG1386) and a National Institutes of Health N.R.S.A. (1-F32 NS10921-01). P. W. R. was supported by a National Science Foundation Pre-Doctoral Fellowship and an NIH training grant. H. R. H. and C. I. B. are Investigators of the Howard Hughes Medical Institute.

\section{REFERENCES}

Anderson, P. (1995). Mutagenesis. Methods Cell Biol. 48, 31-58.

Ausubel, F., Brent, R., Kingston, R., Moore, D., Seidman, J., Smith, J. and Struhl, K. (1987). Current Protocols in Molecular Biology. John Wiley and Sons, New York, NY, USA.

Awasaki, T., Saito, M., Sone, M., Suzuki, E., Sakai, R., Ito, K. and Hama, C. (2000). The Drosophila trio plays an essential role in patterning of axons by regulating their directional extension. Neuron 26, 119-131.

Bar-Sagi, D. and Hall, A. (2000). Ras and Rho GTPases: a family reunion. Cell 103, 227-238.

Bateman, J., Shu, H. and Van Vactor, D. (2000). The guanine nucleotide exchange factor trio mediates axonal development in the Drosophila embryo. Neuron 26, 93-106.

Bellanger, J. M., Lazaro, J. B., Diriong, S., Fernandez, A., Lamb, N. and Debant, A. (1998). The two guanine nucleotide exchange factor domains of Trio link the Rac1 and the RhoA pathways in vivo. Oncogene 16, 147-152.

Bloom, L. and Horvitz, H. R. (1997). The Caenorhabditis elegans gene unc76 and its human homologs define a new gene family involved in axonal outgrowth and fasciculation. Proc. Natl. Acad. Sci. USA 94, 3414-3419.

Bourne, H. R., Sanders, D. A. and McCormick, F. (1991). The GTPase superfamily: conserved structure and molecular mechanism. Nature 349, 117-127.

Branda, C. S. and Stern, M. J. (1999). Cell migration and axon growth cone guidance in Caenorhabditis elegans. Curr. Opin. Genet. Dev. 9, 479-484.

Brenner, S. (1974). The genetics of Caenorhabditis elegans. Genetics 77, 7194.

Chalfie, M., Tu, Y., Euskirchen, G., Ward, W. W. and Prasher, D. C. (1994). Green fluorescent protein as a marker for gene expression. Science $\mathbf{2 6 3}, 802-$ 805 .

Chisholm, A. and Tessier-Lavigne, M. (1999). Conservation and divergence of axon guidance mechanisms. Curr. Opin. Neurobiol. 9, 603-615.

Clark, S. G., Lu, X. and Horvitz, H. R. (1994). The Caenorhabditis elegans locus $\operatorname{lin}-15$, a negative regulator of a tyrosine kinase signaling pathway, encodes two different proteins. Genetics 137, 987-997.

Debant, A., Serra-Pages, C., Seipel, K., O'Brien, S., Tang, M., Park, S. H. and Streuli, M. (1996). The multidomain protein Trio binds the LAR transmembrane tyrosine phosphatase, contains a protein kinase domain, and has separate rac- specific and rho-specific guanine nucleotide exchange factor domains. Proc. Natl. Acad. Sci. USA 93, 5466-5471.

Didsbury, J., Weber, R. F., Bokoch, G. M., Evans, T. and Snyderman, R. (1989). rac, a novel ras-related family of proteins that are botulinum toxin substrates. J. Biol. Chem. 264, 16378-16382.

Erickson, M. R., Galletta, B. J. and Abmayr, S. M. (1997). Drosophila myoblast city encodes a conserved protein that is essential for myoblast fusion, dorsal closure, and cytoskeletal organization. J. Cell Biol. 138, 589603.

Fire, A., Xu, S.-Q., Montgomery, M. K., Kostas, S. A., Driver, S. E. and Mello, C. C. (1998). Potent and specific genetic interference by doublestranded RNA in Caenorhabditis elegans. Nature 391, 806-811.

Forrester, W. C. and Garriga, G. (1997). Genes necessary for C. elegans cell and growth cone migrations. Development 124, 1831-1843.

Forrester, W. C., Perens, E., Zallen, J. A. and Garriga, G. (1998). Identification of Caenorhabditis elegans genes required for neuronal differentiation and migration. Genetics 148, 151-165.

Haataja, L., Groffen, J. and Heisterkamp, N. (1997). Characterization of RAC3, a novel member of the Rho family. J. Biol. Chem. 272, 20384-20388. 
Hall, A. (1998). Rho GTPases and the actin cytoskeleton. Science 279, 509514

Harden, N., Loh, H. Y., Chia, W. and Lim, L. (1995). A dominant inhibitory version of the small GTP-binding protein Rac disrupts cytoskeletal structures and inhibits developmental cell shape changes in Drosophila. Development 121, 903-914.

Hariharan, I. K., Hu, K. Q., Asha, H., Quintanilla, A., Ezzell, R. M. and Settleman, J. (1995). Characterization of rho GTPase family homologues in Drosophila melanogaster: overexpressing Rho1 in retinal cells causes a late developmental defect. EMBO J. 14, 292-302.

Jansen, G., Hazendonk, E., Thijssen, K. L. and Plasterk, R. H. (1997). Reverse genetics by chemical mutagenesis in Caenorhabditis elegans. Nat. Genet. 17, 119-121.

Jin, Y., Jorgensen, E., Hartwieg, E. and Horvitz, H. R. (1999). The Caenorhabditis elegans gene unc-25 encodes glutamic acid decarboxylase and is required for synaptic transmission but not synaptic development. $J$. Neurosci. 19, 539-548.

Kaibuchi, K., Kuroda, S. and Amano, M. (1999). Regulation of the cytoskeleton and cell adhesion by the Rho family GTPases in mammalian cells. Annu. Rev. Biochem. 68, 459-486.

Kimble, J. and Hirsh, D. (1979). The postembryonic cell lineages of the hermaphrodite and male gonads in Caenorhabditis elegans. Dev. Biol. 70, 396-417.

Kiyokawa, E., Hashimoto, Y., Kobayashi, S., Sugimura, H., Kurata, T. and Matsuda, M. (1998). Activation of Rac1 by a Crk SH3-binding protein, DOCK180. Genes Dev 12, 3331-3336.

Letourneau, P. (1996). The cytoskeleton in growth cone motility and axon pathfinding. Perspect. Dev. Neurobiol. 4, 111-123.

Liebl, E. C., Forsthoefel, D. J., Franco, L. S., Sample, S. H., Hess, J. E., Cowger, J. A., Chandler, M. P., Shupert, A. M. and Seeger, M. A. (2000). Dosage-sensitive, reciprocal genetic interactions between the Abl tyrosine kinase and the putative GEF trio reveal trio's role in axon pathfinding. Neuron 26, 107-118.

Lundquist, E. A., Herman, R. K., Shaw, J. E. and Bargmann, C. I. (1998). UNC-115, a conserved protein with predicted LIM and actin-binding domains, mediates axon guidance in C. elegans. Neuron 21, 385-392.

Luo, L., Liao, J., Jan, L. Y. and Jan, Y. N. (1994). Distinct morphogenetic functions of similar small GTPases: Drosophila Drac1 is involved in axonal outgrowth and myoblast fusion. Genes Dev. 8, 1787-1802.

Luo, L., Hensch, T. K., Ackerman, L., Barbel, S., Jan, L. Y. and Jan, Y. N. (1996). Differential effects of the Rac GTPase on Purkinje cell axons and dendritic trunks and spines. Nature 379, 837-840.

McIntire, S. L., Garriga, G., White, J., Jacobson, D. and Horvitz, H. R. (1992). Genes necessary for directed axonal elongation or fasciculation in C. elegans. Neuron 8, 307-322.

McIntire, S. L., Jorgensen, E., Kaplan, J. and Horvitz, H. R. (1993). The GABAergic nervous system of Caenorhabditis elegans. Nature 364, 337341.

Mello, C. and Fire, A. (1995). DNA transformation. Methods Cell Biol. 48, 451-482.

Newsome, T. P., Schmidt, S., Dietzl, G., Keleman, K., Asling, B., Debant, A. and Dickson, B. J. (2000). Trio combines with dock to regulate Pak activity during photoreceptor axon pathfinding in Drosophila. Cell 101, 283294

Nolan, K. M., Barrett, K., Lu, Y., Hu, K. Q., Vincent, S. and Settleman, J. (1998). Myoblast city, the Drosophila homolog of DOCK180/CED-5, is required in a Rac signaling pathway utilized for multiple developmental processes. Genes Dev. 12, 3337-3342.

O'Brien, S. P., Seipel, K., Medley, Q. G., Bronson, R., Segal, R. and Streuli, M. (2000). Skeletal muscle deformity and neuronal disorder in Trio exchange factor- deficient mouse embryos. Proc. Natl. Acad. Sci. USA 97, 12074-12078.
Platt, N., da Silva, R. P. and Gordon, S. (1998). Recognizing death: the phagocytosis of apoptotic cells. Trends Cell Biol. 8, 365-372.

Reddien, P. W. and Horvitz, H. R. (2000). CED-2/CrkII and CED-10/Rac control phagocytosis and cell migration in Caenorhabditis elegans. Nat. Cell Biol. 2, 131-136.

Roberts, A. W., Kim, C., Zhen, L., Lowe, J. B., Kapur, R., Petryniak, B., Spaetti, A., Pollock, J. D., Borneo, J. B., Bradford, G. B. et al. (1999). Deficiency of the hematopoietic cell-specific Rho family GTPase Rac2 is characterized by abnormalities in neutrophil function and host defense. Immunity 10, 183-196.

Sambrook, J., Fritsch, E. F. and Maniatis, T. (1989). Molecular Cloning: A Laboratory Manual. Cold Spring Harbor, NY: Cold Spring Harbor Laboratory Press.

Seeburg, P. H., Colby, W. W., Capon, D. J., Goeddel, D. V. and Levinson, A. D. (1984). Biological properties of human c-Ha-ras1 genes mutated at codon 12. Nature 312, 71-75.

Steven, R., Kubiseski, T. J., Zheng, H., Kulkarni, S., Mancillas, J., Ruiz Morales, A., Hogue, C. W. V., Pawson, T. and Culotti, J. (1998). UNC73 activates the Rac GTPase and is required for cell and growth cone migrations in C. elegans. Cell 92, 785-795.

Sugihara, K., Nakatsuji, N., Nakamura, K., Nakao, K., Hashimoto, R., Otani, H., Sakagami, H., Kondo, H., Nozawa, S., Aiba, A. et al. (1998). Rac1 is required for the formation of three germ layers during gastrulation. Oncogene 17, 3427-3433.

Sulston, J. and Hodgkin, J. (1988). Methods. In The Nematode Caenorhabditis elegans (ed. W. B. Wood), pp. 587-606. Cold Spring Harbor, New York: Cold Spring Harbor Laboratory Press.

Sulston, J. E. and Horvitz, H. R. (1977). Post-embryonic cell lineages of the nematode Caenorhabditis elegans. Dev. Biol. 56, 110-156.

Sulston, J. E., Schierenberg, E., White, J. G. and Thomson, J. N. (1983). The embryonic cell lineage of the nematode Caenorhabditis elegans. Dev. Biol. 100, 64-119.

Svendsen, P. C. and McGhee, J. D. (1995). The C. elegans neuronally expressed homeobox gene ceh-10 is closely related to genes expressed in the vertebrate eye. Development 121, 1253-1262.

Tessier-Lavigne, M. and Goodman, C. S. (1996). The molecular biology of axon guidance. Science 274, 1123-1133.

The C. elegans Genome Sequencing Consortium. (1998). Genome sequence of the nematode $C$. elegans: a platform for investigating biology. Science 282, 2012-2018.

Troemel, E. R., Kimmel, B. E. and Bargmann, C. I. (1997). Reprogramming chemotaxis responses: sensory neurons define olfactory preferences in $C$. elegans. Cell 91, 161-169.

Van Aelst, L. and D'Souza-Schorey, C. (1997). Rho GTPases and signaling networks. Genes Dev. 11, 2295-2322.

White, J. G., Southgate, E., Thomson, J. N. and Brenner, S. (1986). The structure of the nervous system of the nematode Caenorhabditis elegans. Philos. Trans. R. Soc. London 314, 1-340.

Wu, Y. C. and Horvitz, H. R. (1998). C. elegans phagocytosis and cellmigration protein CED-5 is similar to human DOCK180. Nature 392, 501504.

Zallen, J. A., Yi, A. and Bargmann, C. I. (1998). The conserved immunoglobulin superfamily member SAX-3/Robo directs multiple aspects of axon guidance in C. elegans. Cell 92, 217-227.

Zhang, F. L. and Casey, P. J. (1996). Protein prenylation: molecular mechanisms and functional consequences. Annu. Rev. Biochem. 65, 241269.

Zigmond, S. H. (1996). Signal transduction and actin filament organization. Curr. Opin. Cell. Biol. 8, 66-73.

Zipkin, I. D., Kindt, R. M. and Kenyon, C. K. (1997). Role of a new rho family member in cell migration and axon guidance in C. elegans. Cell $\mathbf{9 0}$, 883-894. 